\title{
Review Article \\ New Perspectives on Antiacne Plant Drugs: Contribution to Modern Therapeutics
}

\author{
Priyam Sinha, Shruti Srivastava, Nidhi Mishra, and Narayan Prasad Yadav \\ Herbal Medicinal Products Department, CSIR-Central Institute of Medicinal and Aromatic Plants (CSIR-CIMAP), \\ P.O. CIMAP, Lucknow 226015, India \\ Correspondence should be addressed to Narayan Prasad Yadav; npyadav@gmail.com
}

Received 28 February 2014; Revised 1 July 2014; Accepted 8 July 2014; Published 24 July 2014

Academic Editor: Gail B. Mahady

Copyright (C) 2014 Priyam Sinha et al. This is an open access article distributed under the Creative Commons Attribution License, which permits unrestricted use, distribution, and reproduction in any medium, provided the original work is properly cited.

Acne is a common but serious skin disease, which affects approximately $80 \%$ adolescents and young adults in $11-30$ age group. $42.5 \%$ of men and $50.9 \%$ of women continue to suffer from this disease into their twenties. Bacterial resistance is now at the alarming stage due to the irrational use of antibiotics. Hence, search for new lead molecule/bioactive and rational delivery of the existing drug (for better therapeutic effect) to the site of action is the need of the hour. Plants and plant-derived products have been an integral part of health care system since time immemorial. Therefore, plants that are currently used for the treatment of acne and those with a high potential are summarized in the present review. Most active plant extracts, namely, P. granatum, M. alba, A. anomala, and M. aquifolium exhibit minimum inhibitory concentration (MIC) in the range of 4-50 $\mu \mathrm{g} / \mathrm{mL}$ against $P$. acnes, while aromatic oils of $C$. obovoides, C. natsudaidai, C. japonica, and C. nardus possess MICs $0.005-0.6 \mu \mathrm{L} / \mathrm{mL}$ and phytomolecules such as rhodomyrtone, pulsaquinone, hydropulsaquinone, honokiol, magnolol, xanthohumol lupulones, chebulagic acid and rhinacanthin-C show MIC in the range of $0.5-12.5 \mu \mathrm{g} / \mathrm{mL}$. Novel drug delivery strategies of important plant leads in the treatment of acne have also been discussed.

\section{Introduction}

1.1. General. The comorbidity of chronic skin conditions and mental health disorders has long been known among the emerging groups of psychodermatology and neurodermatology. Recurrently, acne vulgaris is a common dermatological condition allied with depression, anxiety, and other psychological sequelae [1]. Acne is one of the most common multifactorial chronic inflammatory diseases of the pilosebaceous follicles involving androgen induced sebaceous hyperplasia, altered follicular keratinisation, hormonal imbalance, immune hypersensitivity, and bacterial (Propionibacterium acnes) colonisation $[2,3]$. Although acne lacks the urgency of a life-threatening condition without impairing the overall fitness, it produces long term ramifications that can be momentous coming up with cutaneous and emotional scars lasting lifetime [4]. It hampers an individual's confidence causing physical, social, and psychological sufferings and reduces self-esteem and emotional distress caused by perceived disfigurement $[5,6]$.
The clinical manifestations of acne include seborrhoea (excess grease), noninflammatory lesions (open and closed comedones), inflammatory lesions (papules and pustules), and various degrees of scarring due to cyst formation [2]. The distribution of acne corresponds to the highest density of pilosebaceous units; it is distributed over face, neck, upper chest, shoulders, and back. According to the lesion type, acne can be classified into noninflammatory (purely comedonal acne) and inflammatory acne (mild papular, scarring papular, and nodular). Grading upon its severity, it can be categorized into mild, moderate, and severe acne. Mild acne comprises of open and closed comedones $(<20)$, inflammatory lesions $(<15)$ with total lesions not exceeding 30 . Likewise, in moderate acne numerous papules and pustules are observed along with comedones (20-100), inflammatory lesions (1550) whereas total lesions in the range of 30-125. Severe acne is diagnosed with extensive lesions including nodules and scarring together with cysts $(>5)$, total comedone count $(>100)$, total inflammatory count $(>50)$ and total number of lesions more than $125[7,8]$. 
1.2. Epidemilogy. Virtually, no mortality is evidenced in this disease, but there is often noteworthy physical and psychological morbidity. On the word of statistics, globally around $85 \%$ of young adults aged $12-25$ years old, approximately $8 \%$ of adults aged 25-34 years old, and 3\% of adults aged 35-44 years old experience certain degree of acne [9]. On an average $42.5 \%$ of men and $50.9 \%$ of women continue to suffer from the disease in their twenties [5]. Recent findings concluded that, in $30 \%$ of women, acne can persist during their entire fertile period [10]. Affecting 40 to 50 million people in USA per year, a significant number of adults continue to struggle with acne even after their teenage years. One population study in Germany found that $64 \%$ of individuals 20 to 29 years old and $43 \%$ of individuals 30 to 39 years old had visible acne. Another study from Germany of more than 2000 adults showed that $3 \%$ of men and $5 \%$ of women still had definite mild acne at the age of 40 to 49 years [11]. In a study of 309 subjects in southern India, the closed comedones differed from open comedones by a factor of $4.9: 1$. A total of 186 patients $(60.2 \%)$ had grade 1 acne vulgaris and $85(27.5 \%)$, $8(2.6 \%)$, and $30(9.7 \%)$ patients had grades 2, 3, and 4, respectively, [12]. Recently, it was noted that heritability of acne is almost $80 \%$ in first degree relatives and is more severe in those with a positive family history. Acne was found to be more frequent and severe among smokers following a dose dependent association [13]. The burden of acne in terms of cost to society was not well demarcated, but its predominance endorsed the high costs bestowing a substantial financial burden to the community. In a recent report in USA, the cost of acne is estimated to be 3 billion dollars per year in terms of treatment and loss of productivity [11].

1.3. Pathophysiology of Acne. The multifactorial pathogenesis of acne instigates at the pilosebaceous unit that consisted of multilobulated sebaceous glands, an epithelial lined follicular canal, and a hair [14]. Pathophysiology of acne is attributed to different notable factors such as sebaceous gland hyperplasia with seborrhoea, alteration in the quality of sebum lipids, inflammatory processes besides immune response, dysregulation of the hormone microenvironment, interaction with neuropeptides, and follicular hyperkeratinization followed by proliferation of Propionibacterium acnes within the follicle $[15,16]$.

The relation between androgen level and sebum production in acne vulgaris has been preestablished. The first factor in the genesis of acne is the androgen induced hypertrophy of sebaceous glands with overproduction of sebum [17]. The sebaceous glands possess steroid metabolizing enzymes which convert dehydroepiandrosterone (DHEAS) to dihydrotestosterone (DHT). Furthermore, two subtypes of 5- $\alpha$ reductase isozymes, that is, type 1 and type 2 , expressed in the scalp, chest, sebaceous glands, genitourinary tissue, and dermal papillae as well as in hair follicles, convert testosterone to the more active DHT [5]. Excess sebum production causes occlusion in the pilosebaceous unit and increases cell turnover in the follicular canal. Moreover, in the second factor of pathogenesis, pilosebaceous follicles are surrounded by macrophages and inflammatory mediators expressing Toll like receptors (TLR2) on their surface. TLR2 activation leads to transcription of nuclear factor triggering and thus heading towards the expression of cytokines, such as interleukin-1 $\beta$ (IL-1 $\beta$ ), IL-8, and granulocyte macrophagecolony stimulating factor (GM-CSF), initiates and propagates the inflammatory response that further induces keratinocyte hyperproliferation [18]. Retention of desquamated keratinocytes within the pilosebaceous unit initiates follicular plugging and obstruction which triggers obliteration of the normal architecture of the follicle and formation of a thinwalled cystic lesion that is the comedo. As the keratinocytes and sebum continue to accumulate, the microcomedo wall eventually ruptures prompting inflammation [19].

Developing comedone covers greasy plugs comprising mixture of keratin, sebum, bacteria, and the superficial layer of melanin which may appear as a black head or a white head. Comedones when outburst through skin surface having central black appearance (due to the oxidation of tyrosine to melanin by tyrosinase) are called "black heads" or open comedones. However, impaction and distension of the follicle with improperly desquamated keratinocytes and sebum result in the development of "white heads" or closed comedones which remain underneath the skin surface as closed follicles $[3,20]$. Depending upon the severity of pathologic conditions, these lesions represent a papule, pustule, nodule, and cyst.

Propionibacterium acnes is an anaerobic Gram-positive bacterium that produces propionic and acetic acid. In the follicular infundibulum of comedones, a large number of $P$. acnes are observed because comedones are filled with a lipid substrate as a nutrient source proposing it as an ideal site for anaerobes. Ultrastructural observation shows that $P$. acnes are 0.4 to $0.7 \mu \mathrm{m}$ in width and 3 to $5 \mu \mathrm{m}$ in length, possessing a ribosome rich cytoplasm and a relatively thick cell wall composed of peptidoglycan [17]. P. acnes is involved in the development of inflammatory acne by activating complements and metabolizing sebaceous triglycerides into fatty acids that irritate the follicular wall and surrounding dermis. It also produces exoenzymes and chemotactically attracts neutrophils [4]. P. acnes produces lipases, proteases, and hydrolases, contributing to inflammation and tissue destruction; expresses stress proteins which are responsible for comedonal rupture; and also incites an inflammatory response by acting on TLR-2. This may stimulate the expression of cytokines, such as IL- 6 and IL- 8 by follicular keratinocytes and IL- 8 and IL-12 in macrophages, which is thought to activate hyperkeratinization, cell adhesion, follicular obstruction, and inflammation. The sequential phenomena lead to vascular and cellular events of inflammatory response and cause follicular disruption giving rise to acneiform lesions in the form of papules, pustules, and nodules.

1.4. Molecular Targets for Acne Treatment. Human sebocytes are biologically and metabolically very active cells and consequently express numerous receptors [21]. Many ligands bind to these receptors and produce varied responses altering the cell proliferation, cytokine production, and lipid synthesis, ultimately involved directly or indirectly in acne pathogenesis. After reviewing the literature, possible ligands 
have been enlisted, which trigger cell proliferation, cytokine expression, and lipogenesis after binding with their respective receptors. Individual ligand (agonist) has its own mode of action causing acne and hence requires specific antagonist which will bind to these receptors and cure acne. As far as acne treatment and management are concerned, all these pathways should be considered and recognised prior to treatment selection.

(1) Neuropeptides like vasoactive intestinal polypeptide (VPAC), neuropeptide Y and calcitonin gene-related peptide, and Substance P usually bind on VPAC receptors which are present on sebocytes of sebaceous glands. The consequences of binding are cytokines expression, sebocyte proliferation/differentiation, and upregulation of lipogenesis $[16,17,21]$.

(2) PRAR ligands are such as leukotriene B4 (5lipoxygenation product derived from arachidonic acid), a well-known natural ligand of PPAR $\alpha$ receptors present in mitochondria, peroxisomes, and microsomes of sebocytes. This ligand is known to induce lipogenesis in cultured human sebocytes and thereby, 5-lipoxygenase inhibitors could be considered to reduce lipogenesis and acne lesions.

(3) Histamine bound to the histamine 1 receptor and induces squalene synthesis in SZ95 sebocytes. As a result, lipid peroxidation takes place and squalene peroxide is produced as a byproduct. Further, it induces inflammatory responses as well ascomedogenesis and sometime interferes with sebocytesdifferentiation and sebogenesis [21, 22].

(4) Insulin in higher concentration and insulin like growth factors-1 activate IGF-I receptor which is expressed on SZ95 sebocyte cell surface. IGF-I amplifies lipid accumulation in sebocytes in a dose dependent manner. It is also known to stimulate $5 \alpha$-reductase, adrenal and gonadal androgen synthesis, androgenreceptor signal transduction, and hence sebocyte proliferation $[23,24]$.

(5) Fibroblast growth factor (FGF) secreted by keratinocyte derived interleukin- $1 \alpha$ stimulated fibroblast and binds on FGF receptor $2 \mathrm{~b}$ present in suprabasal spinous layer of the epidermis and sebocytes. FGF plays a crucial role in controlling epithelial proliferation and differentiation. At the same time androgen mediated upregulation of FGFR2b signalling is also possible which brings out follicular hyperkeratinization and sebaceous gland hypertrophy thereby [25, 26].

(6) Corticotrophin releasing hormone and urocortin bind to the CRH-receptor 1 (CRH-R1) at human sebocytes and reduces sebocyte proliferation, upregulates $3 \beta$ hydroxysteroid dehydrogenase, stimulates lipogenesis and keratinocyte differentiation, and increases in local inflammation by expressing IL- 6 and IL-8 [27-29].

(7) $\beta$-Endorphin binds with $\mu$ opiate receptors present on sebaceous glands which stimulates lipogenesis and specifically increases the amount of fatty acids to an extent similar to linoleic acid in sebocytes.

(8) $\alpha$-Melanocyte stimulating hormone binds at melanocortin 1 and 5 receptors (MC-1R and MC-5R), located at the cellular surface of sebocytes. MC-1R regulates inflammation in SZ95 sebocytes and exhibits a stronger expression in acne involved sebaceous glands.
(9) Retinoic acid (RA) and 9-cis retinoic acid are the ligands of retinoic acid receptors (RAR $\alpha$ and $\gamma$ ) and retinoid $\mathrm{X}$ receptors $(\mathrm{RXR} \alpha)$ which are the predominant retinoid receptors in human sebocytes that regulate cell proliferation/differentiation.

(10) Vitamin $D_{3}$ binds to vitamin D receptors and induces time and dose dependent modulation of cell proliferation, cell cycle regulation, lipid content, and IL6 and IL8 secretion by cultured sebocytes.

(11) P. acnes moieties stimulate TLR receptors (TLR$2,4,6$ ) on keratinocytes. TLR activation results in the release of inflammatory cytokines (TNF- $\alpha$, IL-6, and IL- 8 ) by keratinocytes $[16,21]$.

(12) Matrix metalloproteinases are present in sebum and originate in keratinocytes and sebocytes. Sebum contains MMP-1, MMP-13, TIMP-1, TIMP-2, proMMP-9, and MMP13 , among which the latter two decreased with isotretinoin parallel to clinical improvement. The drug inhibited the arachidonic acid, induced secretion and mRNA expression of MMPs in HaCaT keratinocytes [30, 31].

(13) Dipeptidyl peptidase IV and aminopeptidase $N$ are ectopeptidases which bind on particular receptors and participatein regulation of sebocytes. DP IV and APN enhance proliferation, reduce terminal differentiation, and stimulate total neutral lipid production. Furthermore, these promoted proliferation and IL-2 production of $P$. acnes stimulated T cells ex vivo and suppressed the expression of the immunosuppressive cytokine transforming growth factor- $\beta 1[32,33]$.

Altered lipogenesis, sebum production, hyperkeratinization, proliferation/differentiation of sebocytes, and cytokine expression may be reason for the formation of acne lesions. Acne management could be done efficiently only when the exact mechanism involved in the pathogenesis is known. The above targets could be considered during the assessment of the antiacne potential of the eminent active moieties in near future because these mechanisms play direct or indirect role in the acne pathogenesis.

\section{Challenges in Acne Treatment}

The management of acne is a long-standing process which must be customized to each patient. After the diagnosis of the disease, a suitable therapeutic strategy is the root of its treatment. Based on the type and severity of acne, the selection of proper medication depending on its mechanism of action relating its ability to address one or more of the pathogenic factors is the major challenge allied with its treatment selection. In this context, treatment of acne renders several challenges inspite of numerous therapeutic agents available.

2.1. Antibiotic Resistance. The persistent relevance of antibiotics in acne treatment is coupled with the risk of emerging resistant bacteria. The increase in antibiotic resistance is multifactorial, involving the specific nature of the relationship of bacteria to antibiotics. Consequently, there are adequate motives to search for alternative remedies to solve this problem. To overcome antibiotic resistance as well as the 
high treatment cost, medicinal plants have been studied as alternative treatments for acne.

\subsection{To Surmount the Glitches Allied with Conventional For-} mulations of Antiacne Drugs. The followup phase of management requires a framework for approaching treatment modification that may include concepts such as nonexistence of effectual system for delivery of antiacne drugs. Antiacne drugs incorporated in conventional system either cannot reach the pilosebaceous unit at defined concentration or may not release the active moiety leading to their subtherapeutic levels. The problem can be resolved by employing futuristic approaches that is targeting the active molecule directly to the pilosebaceous unit or sebaceous gland which can eradicate the underlying microbial flora of $P$. acnes and inflammatory mediators responsible for acne vulgaris. Novel drug delivery system (NDDS) may be a preference to minimize the glitches related to conventional formulations like variation in drug efficacy and absorption, physicochemical characteristics of the active molecules and carriers or their improper incorporation in the conventional vehicles.

2.3. Non-Availability of Appropriate Animal Model. A major limitation in the development of an appropriate drug and delivery system for acne is the unavailability of a suitable animal model that can certainly mimic various pathophysiologic characteristics in humans.

\section{Current Management Approaches}

Grounded on the type and severity of acne lesions, rational use of existing treatment choices is currently an essential component of successful acne therapy. Mainstream acne management associates topical treatment either as monotherapy or in combination with a systemic drug therapy depending on the severity of acne. The current armamentarium available consists mainly of topical and oral retinoids, topical antimicrobials, systemic antibiotics, keratolytics, and hormonal therapy that consisted of oral contraceptives as well as androgen blocking agents, in addition to combination therapy of all the aforementioned agents.

Topical retinoids (vitamin A derivatives) are comedolytic agents which reduce abnormal mitosis of keratinocytes, hyperkeratinization, and inflammation. Modified slow release formulations and a third generation retinoid adapalene are reported to be less irritating. Azelaic acid is a naturally occurring dicarboxylic acid with modest antibacterial and comedolytic effects. Erythromycin and clindamycin are the most commonly used topical antibiotics in acne. They are useful in inflamed lesions with associated antibiotic resistant as a major problem. Oral antibiotics, namely, tetracyclines and macrolides, are prescribed in moderate to severe inflammatory acne, thereby precluding the practicality of applying topical therapies. In addition to the above mentioned antibiotics, trimethoprim, sulfamethoxazole, and ciprofloxacin are also used. In multiple trials, topical combination therapies are more effective than monotherapy as they are capable of targeting multiple pathogenic mechanisms. A number of fixed dose topical combination products are available including adapalene-BPO $(0.1 \% / 2.5 \%)$, clindamycin-BPO (1\%/5\% gel), erythromycin-BPO (3\%/5\% gel), erythromycintretinoin (4\%/0.025\% solution), and clindamycin-tretinoin $(1.2 \% / 0.025 \%$ gel). Oral contraceptives, including ethinyl estradiol in combination with cyproterone acetate, levonorgestrel, norgestimate, desogestrel, drospirenone, and ethynodiol diacetate, inhibit serum androgen levels, increase sex hormone binding globulin, and improve acne regardless of the type of progestin or concentration of estrogen. A detailed overview of these therapeutic approaches together with their mode of action and associated adverse effects [34-42] has been tabulated in Table 1 .

\section{Plants Having Antiacne Potential}

The expedition for measures to combat acne continues to be a major research and development initiative in pharmaceutical and personal care industries [43]. The sustained application of antibiotics entails the risk of emerging resistant bacteria which is needless to mention. The development of antibiotic resistance is multifactorial, involving the specific nature of the relationship of bacteria to antibiotics [44]. Subsequently, there are sufficient purposes for searching alternative remedies that work out and resolve these problems. To overcome antibiotic resistance as well as the high treatment cost, medicinal plants have been studied as alternative treatments for diseases. As an alternative approach, numerous reports have indicated the possibility of using medicinally potent plant actives to counter the growth of the bacteria and inflammatory response. Occurrence of 250,000-500,000 plant species offers a great potential for screening phytotherapeutic agents which can be utilized for acne management. Traditional herbal medicines provide an interesting and largely unexplored source for the development of new drugs. Traditional medicines and natural products offer a great hope in the identification of bioactive lead compounds and their development into drugs for the treatment of acne vulgaris [20]. An attempt is also being made to enumerate the possible leads from traditional medicinal system for the treatment of acne with an ongoing search for novel biologically active botanical agents.

4.1. Plant Extracts. Plant extracts are therapeutically desired; medicinally active portions of medicinal plants are separated from inactive or inert components using selective solvents by standard extraction procedures like decoction, maceration, infusion, digestion, percolation, and soxhlet extraction. These are obtained in the form of decoctions, infusions, tinctures, semisolid, and powdered extracts. Some of the active plant extracts with antiacne properties have been discussed below.

Echinacea purpurea extract provided antiacne effect by inhibiting proliferation of $P$. acnes and reversing the bacterial induced inflammation. It also normalized elevated cytokine levels including IL-6 and IL-8 (CXCL8) in cell culture models of human bronchial epithelial cells and skin fibroblasts through cytokine antibody arrays [45]. Garcinia mangostana 


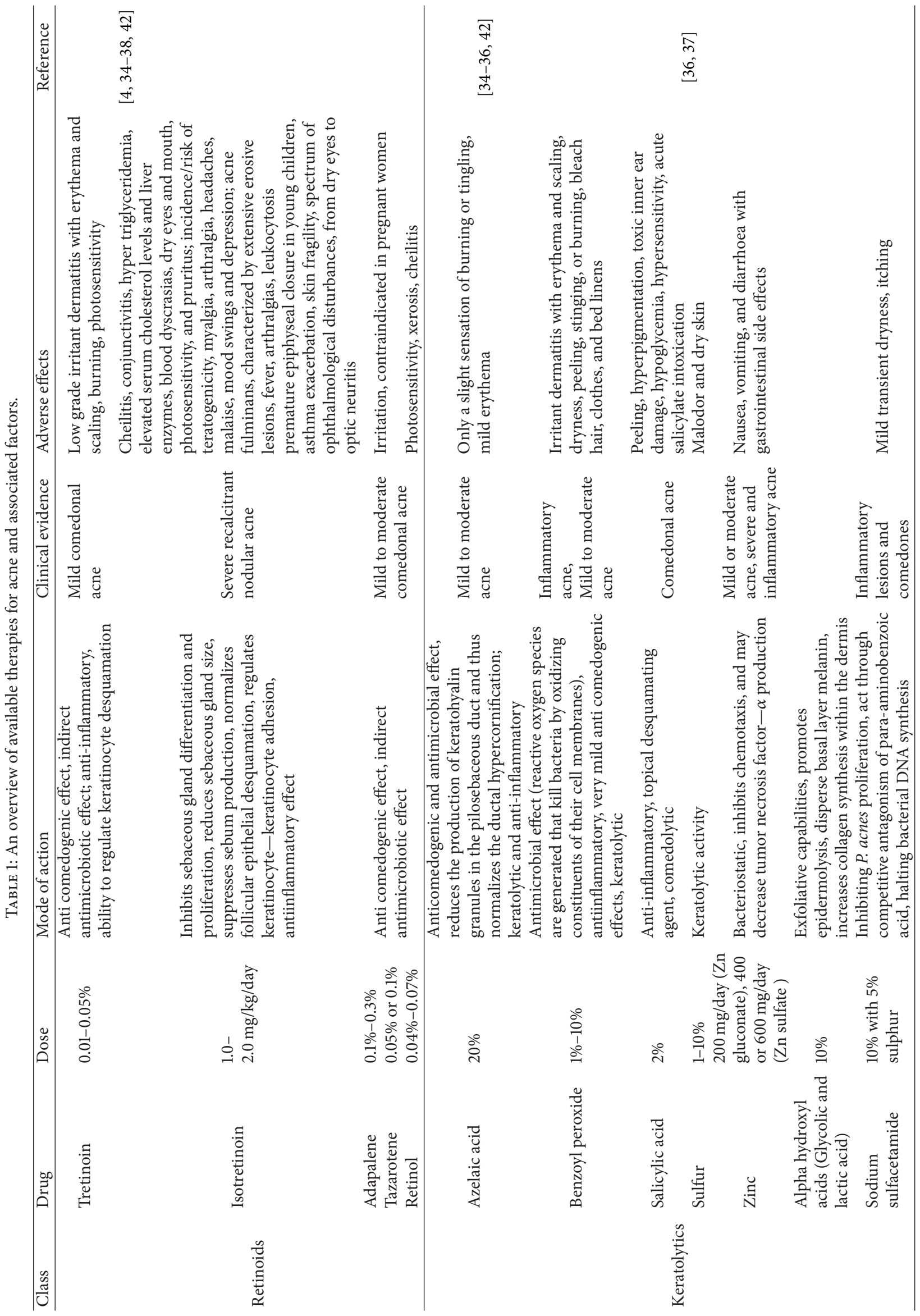




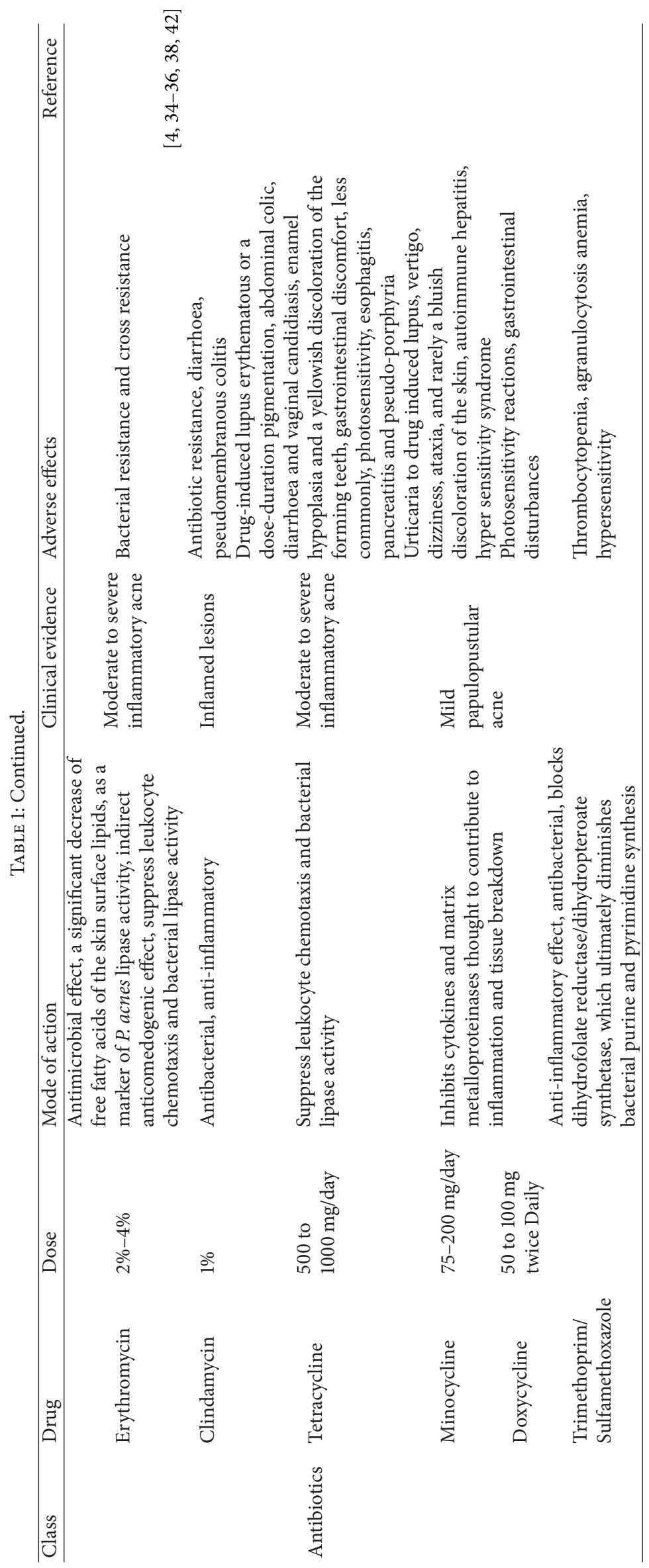




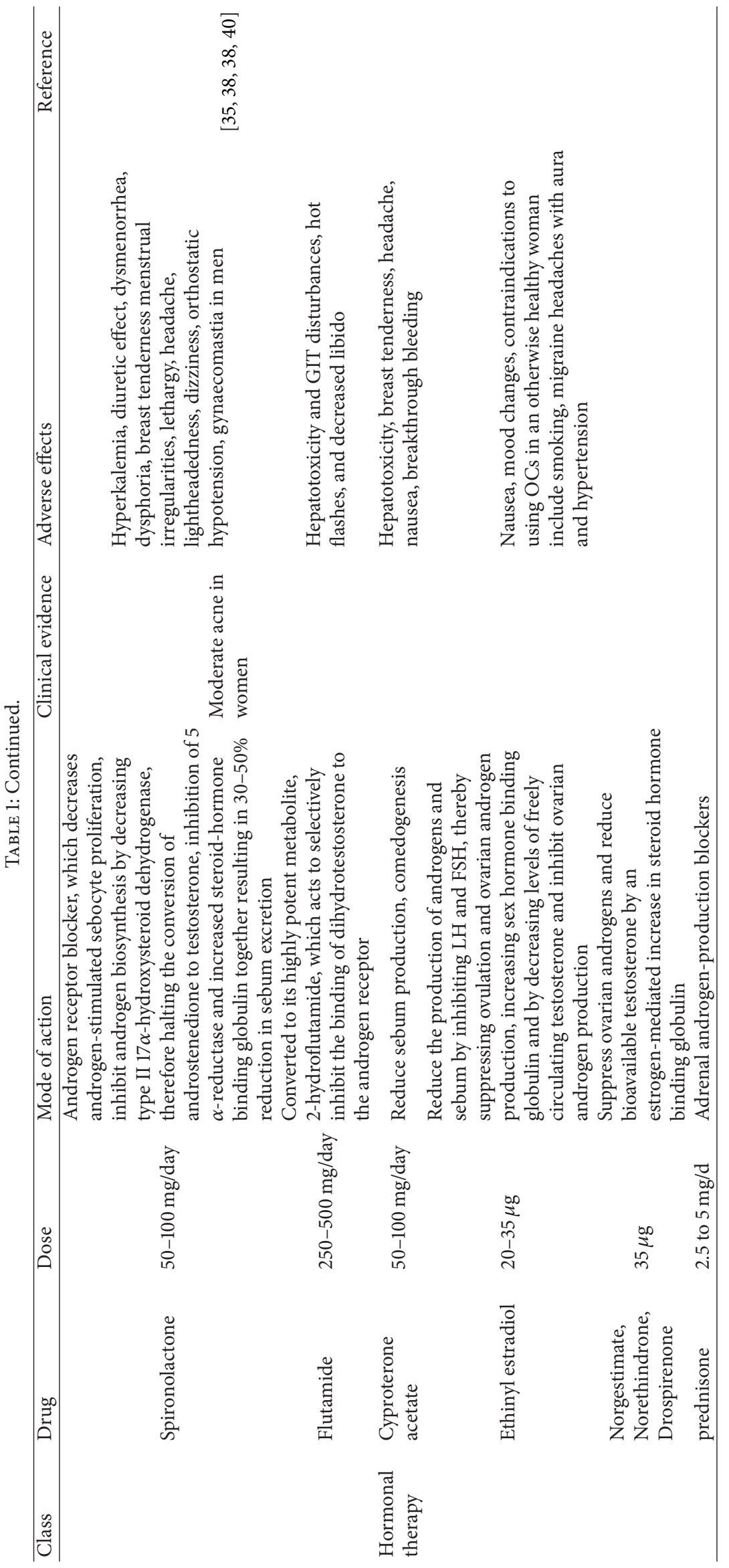


is well known for its marked antiacne potential, and the dichloromethane extract of the pericarp exhibited the most potent antibacterial effect against both $P$. acnes and S. epidermidis with highest amount of $\alpha$-mangosteen as quantified by HPLC. The MIC values for $P$. acnes and S. epidermidis were the same $(0.039 \mathrm{mg} / \mathrm{mL})$, whereas the $\mathrm{MBC}$ values were 0.039 and $0.156 \mathrm{mg} / \mathrm{mL}$, respectively, [46]. The extracts reduced the TNF- $\alpha$ production as determined by ELISA, effective in scavenging free radicals, and suppressed the production of proinflammatory cytokines [47]. In addition to these plants, Senna alata (0.625-2.5 mg/mL MIC), Eupatorium odoratum (0.625 mg/mL MIC), and Barleria lupulina $(1.25-2.5 \mathrm{mg} / \mathrm{mL}$ MIC) also showed strong inhibitory effects against $P$. acnes based on broth dilution method [44].

Moreover, Camellia sinensis polysaccharide showed strong inhibitory activities against hemagglutination mediated by pathogens $H$. pylori, P. acnes, and S. aureus with MIC in the range of $0.01-0.5 \mathrm{mg} / \mathrm{mL}$. Findings proposed that the adhesion of these pathogens to hostcell lines exhibited selective antiadhesive effect of $C$. sinensis only against $P$. acnes pathogens [48]. Furthermore, 3\% of green tea extract emulsion was recognised to reduce skin sebum production in healthy human volunteers using sebumeter [49]. In a comparative study, methanolic extract of C. sinensis possessed utmost antibacterial activity against $S$. aureus, $S$. epidermis, and P. acnes (MIC $1.25 \mathrm{mg} / \mathrm{mL}$ ), when compared to extracts of Glycyrrhiza glabra and Calendula officinalis by agar disc diffusion method (due to the presence of alkaloids, flavonoids, glycosides, and terpenoids) recommending them as responsible phytoconstituents for the antiacne activity [50].

Additionally, Punica granatum rind extract containing $13 \%$ ellagic acid exhibited potent bacteriostatic effect against P. acnes (MIC $15.6 \mu \mathrm{g} / \mathrm{mL}$ ), S. aureus, and S. epidermidis (MIC $7.8-15.6 \mu \mathrm{g} / \mathrm{mL}$ ). It also inhibits nitric oxide production by murine macrophage like RAW 264.7 cells and the release of b-hexosaminidase from antigen stimulated rat basophilic leukemia cells revealing its antiallergic properties [51]. Potent extract of Psidium guajava and Juglans regia leaf extracts showed in vitro inhibitory effect on $P$. acnes and other organisms isolated from acne lesions of thirty-eight patients by disk diffusion method [52]. Selaginella involvens extract inhibited nitric oxide production, iNOS/IL-1 $\beta$ expression, and cytokines (IL-1 $\alpha$ and IL-8) in keratinocytes along with antioxidant effect in a dose dependent manner [53]. Terminalia arjuna bark extract with flavonoid and tannin fractions were tested against $P$. acnes and $S$. epidermidis, in which flavonoid fraction (MIC $0.315 \mathrm{mg} / \mathrm{mL}$ ) and its $2 \%$ cream formulation were found to be more effective [54].

The extracts and formulations of white tea, witch hazel, and rose have a protective effect on fibroblast cells and elicited a significant decrease in the amount of IL- 8 produced by fibroblast cells against hydrogen peroxide induced damage. In addition to this, white tea and rose also showed considerable anticollagenase, antielastase, and antioxidant activities [55]. Methanolic extracts of Rosa damascene, Eucommia ulmoides, and Ilex paraguariensis were found to inhibit the growth of $P$. acnes with respective MICs of $2,0.5$, and $1 \mathrm{mg} / \mathrm{mL}$. In addition, the latter two reduced the secretion of proinflammatory cytokines such as tumour TNF- $\alpha$, IL- 8 , and IL- $1 \beta$ by human monocytic THP-1 cells pretreated with heat killed $P$. acnes at a concentration of $0.1 \mathrm{mg} / \mathrm{mL}$ [56]. In a study, Rubia cordifolia, Curcuma longa, Hemidesmus indicus, and Azadirachta indica extracts caused significant suppression of reactive oxygen species from polymorphonuclear leukocytes and proinflammatory cytokine induced monocytes [57]. Coscinium fenestratum extract with MIC values of $0.049 \mathrm{mg} / \mathrm{mL}$ against $P$. acnes and S. epidermidis and MBC values of 0.049 and $0.165 \mathrm{mg} / \mathrm{mL}$, respectively, proved its antiacne activity. Similarly, Tephrosia purpurea, Euphorbia hirta, Curcubito pepo, and Eclipta alba had strong inhibitory effects against $P$. acnes [58]. Leaves and seeds of Borago officinalis, Linum bienne, and Ruta graveolens and aerial parts of Malva sylvestris and Rubus ulmifolius were known to effectively treat acne $[59,60]$.

Morus alba root extract showed MIC values $15.6 \mu \mathrm{g} / \mathrm{mL}$ and $3.1 \mu \mathrm{g} / \mathrm{mL}$ against $P$. acnes and S. epidermidis, respectively. Extracts from Phellodendron amurense, Albizzia julibrissin, and Poncirus trifoliate also produced remarkably low MIC values against both the pathogens [61]. Likewise, Anacardium pulsatilla containing polyphenols and Podocarpus nagi containing flavonols are recognized to be effective against $P$. acnes [62]. Another well-known plant is Angelica anomala which had strong inhibitory effects against $P$. acnes and $S$. epidermidis with MIC values of $15.6 \mu \mathrm{g} / \mathrm{mL}$ and $126 \mu \mathrm{g} / \mathrm{mL}$, respectively. Mollugo pentaphylla, Matteuccia orientalis, and Orixa japonica also inhibited the growth of both pathogens, along with the reduction in $P$. acnes induced secretion of IL8 and TNF- $\alpha$ in THP-1 cells [63]. Caesalpinia sappan and Intsia palembanica were noted as potent antiacne plants based on their antibacterial (MIC $0.13 \mathrm{mg} / \mathrm{mL}$; MBC $0.25 \mathrm{mg} / \mathrm{mL}$ ), lipase inhibitory, and antioxidative properties [64].

The organic extracts of Elephantorrhiza elephantina, Ekebergia capensis, Eucalyptus camaldulensis, and Harpephyllum caffrum displayed noteworthy activity against $P$. acnes with MIC values between 0.05 and $1.00 \mathrm{mg} / \mathrm{mL}$ [65]. In another study, ethanolic extracts of Ammnia baccifera, Hibiscus syriacus, Quercus infectoria, Berberis aristata, Couroupita guianensis, and Symplocos racemosa have shown antiacne potential, but Symplocos racemosa was found to be most effective with MIC value of $0.044 \mathrm{mg} / \mathrm{mL}$ [66]. Pisum sativum seeds containing proteins, lecithins, carbohydrates, and Trifolium pretense having isoflavones are used in treating acne [67].

Vitex agnus-castus has been shown to be effective in the treatment of premenstrual acne. Antioxidative and antimicrobial properties of Usnea barbata, Solanum dulcamara, and Saccharomyces cerevisiae are responsible for their antiacne potential [68]. A methanol-dichloromethane extract of different Eucalyptus species, namely, E. globulus, E. maculata, and E. viminalis possessed potent antiacne activity. Oregon grape crude root extracts and its alkaloids berberine and jatrorrhizine showed MIC values between 5 and $50 \mu \mathrm{g} / \mathrm{mL}$ against $P$. acnes in vitro [69]. A gel formulation containing $0.1 \%$ of anthraquinone rich fraction from the roots of $R$. cordifolia exhibited potent activity against $P$. acnes, $S$. epidermidis, and $M$. furfur when compared with standard clindamycin gel by cup plate diffusion method [70]. In another study, MIC value 
of the extract against $P$. acnes was found to be $600 \mu \mathrm{g} / \mathrm{mL}$ by broth dilution method and produced a significant zone of inhibition [71].

Terpenoids of Gossypium barbadens, possess antiacne properties owing to its antimicrobial and antioxidant effects. Eucommia ulmoides was found to inhibit $P$. acnes with MIC $0.5 \mathrm{mg} / \mathrm{mL}$ and reduce the secretion of proinflammatory cytokines. Radical scavenging activity of Phyllanthus emblica, COX-2, and NO expression inhibiting activity of Aralia continentalis, inhibitory effect on lipid peroxidation by Clerodendrum indicum, and suppression of PGE2 production by Clerodendron trichotomum enables their use against inflammatory acne $[72,73]$. Additionally, the extracts obtained from Aglaia roxburghiana fruits, Euonymus pendulus bark, Emblica officinalis fruits, and Raphanus sativus were also active and inhibited lipid peroxidation [73, 74]. Lygodium japonicum extracted by the pressure assisted water extraction noticeably possessed antioxidant and antibacterial activity with MIC 2.59, 3.33, and $7.37 \mathrm{mg} / \mathrm{mL}$ against Listeria monocytogenes, Salmonella typhimurium, and P. acnes, respectively, [75].

4.2. Essential Oils. Natural essential oil, a concentrated hydrophobic liquid containing volatile aroma compounds, is obtained from plant organs by water distillation, steam distillation, and cohobation in addition to enfleurage method. Recently, these essential oils have also been explored for their wide application in acne management.

A single-blind, randomized clinical trial on 124 patients with mild to moderate acne concluded that both 5\% Melaleuca alternifolia (tea tree oil) and 5\% benzoyl peroxide lotion encouragingly reduced the number of inflamed and noninflamed lesions with considerably fewer side effects from tea tree oil [76]. In tea tree oil, terpinen-4-o1, $\alpha$-terpineol, and $\alpha$-pinene were found to be active against $S$. aureus, $S$. epidermidis, and P. acnes [77]. From a study of 60 patients with mild to moderate acne, tea tree oil in terms of total acne lesion count and acne severity index was found to be highly effectual in treating acne [78]. Similarly, the essential oil of Zingiber cassumunar (Plai oil) exhibits antimicrobial activity against a wide range of bacteria (MBC $0.62 \%$ against $P$. acnes), dermatophytes, and yeasts, confirming its potential application against acne [79].

Moreover, Thymus quinquecostatus essential oil retains considerable antibacterial, antioxidant, antielastase, and antiinflammatory effects against acne inducing bacteria. It also induces low cytotoxicity in human cell lines proving itspossible effectiveness for acne treatment [80]. Additionally, antibacterial activity of rosemary essential oil against $P$. acnes (MIC $0.56 \mathrm{mg} / \mathrm{mL}$ ) was probably attributed to its bioactive components such as 1,8-cineole, $\alpha$-pinene, camphor, and camphene. The atomic force microscopy and phase images confirmed that, at lower concentration, rosemary essential oil attached to the surface of bacterial cell and with increase in concentration, the bacterial bodies were severely damaged [81].

Furthermore, volatile oils from Eucalyptus globulus (MIC and $\mathrm{MBC} 9.38 \mathrm{mg} / \mathrm{mL}$ ) and Psidium guajava leaves (MIC $9.38 \mathrm{mg} / \mathrm{mL}, \mathrm{MBC} 37.50 \mathrm{mg} / \mathrm{mL}$ ) exhibited antimicrobial activity as determined by agar diffusion and microdilution methods against $P$. acnes due to $\gamma$-terpinene and $\alpha$-pinene [82]. The in vivo rat sebaceous gland model concluded that eucalyptus oil decreases sebum production by reducing the size of sebaceous glands, thus controlling the spread of acne [83].

Essential oil of Abies koreana possessed excellent antibacterial activities against drug susceptible and resistant $P$. acnes and S. epidermidis. In addition, it reduced the LPS-induced secretion of TNF- $\alpha$, IL-1 $\beta$, IL-6, NO, and PGE2 in RAW 264.7 cells, indicating its anti-inflammatory effects [84]. Similarly, the antibacterial activity of coriander oil against P. acnes and S. epidermidis was investigated and MIC values were found to be $1 \%$ and $1.1 \% \mathrm{v} / \mathrm{v}$, respectively, by agar dilution method [85]. In vitro antiacne potential of Citrus obovoides and Citrus natsudaidai oils was proved as they exhibited antibacterial activity against $P$. acnes and S. epidermis (MIC $0.31 \mu \mathrm{L} / \mathrm{mL}$, \& $2.5-10 \mu \mathrm{L} / \mathrm{mL}$ ) as well as superoxide anion radical scavenging activity. They also reduced $P$. acnes induced secretion of IL-8 and TNF- $\alpha$ in THP-1 cells [86]. Cryptomeria japonica essential oil, containing kaurene, enemol, $\gamma$-eudesmol, and sabinene, has potent antimicrobial activity against $P$. acnes and S. epidermidis (MIC $0.16-10 \mu \mathrm{L} / \mathrm{mL}$ ) and has inhibitory effects on NO, $\mathrm{PGE}_{2}, \mathrm{TNF} \alpha$, IL- $1 \beta$, and IL- 6 production in lipopolysaccharide activated macrophages [87].

Another well-known Ocimum gratissimum oil preparation in a cetomacrogol blend base was well tolerated, was more effective, and reduced acne lesions faster than benzoyl peroxide $10 \%$ lotion showing its effectiveness in the management of acne [88]. It was indicated that aloe vera gel enhanced the antiacne properties of Ocimum oil, and their combination is more effective than $1 \%$ clindamycin in the treatment of acne [89]. From a study, it was concluded that essential oils of Cymbopogon nardus, Cymbopogon citratus, Citrus hystrix, Ocimum sanctum, Ocimum basilicum, Zingiber cassumunar, and Zingiber officinale possessed antimicrobial, anti-inflammatory, and antioxidant properties. Among these, Cymbopogon nardus oil (citronella oil) was most active against $P$. acnes (MIC $0.005-0.3 \mu \mathrm{L} / \mathrm{mL}$ ). In addition to this, all the essential oils except kaffir lime oil demonstrated notable free radical scavenging activity. The major components such as eugenol in holy basil oil and d-limonene in kaffir lime oil were suggested to contribute to this activity [90]. In another study, ten essential oils, Mentha spicata, Zingiber officinale, Citrus limon, Citrus paradisi, Jasminum grandiflora, Lavandula angustifolia, Matricaria chamomilla, Thymus vulgaris, Rosa damascene, and Cinnamomum zeylanicum were identified to have antiacne properties against $P$. acnes. It was witnessed that thyme, cinnamon, and rose essential oils exhibited the best antibacterial activities with MIC of $0.016 \%, 0.016 \%$, and $0.031 \% \mathrm{v} / \mathrm{v}$, respectively, [91].

In a study of ocimum oils, Ocimum basilicum (sweet basil) and Ocimum sanctum (holy basil) essential oils along with their microemulsions were screened for their in vitro activity against $P$. acnes using disc diffusion method indicating that the MIC values of sweet basil and holy basil oils were $2.0 \%$ and $3.0 \% \mathrm{v} / \mathrm{v}$, whereas microemulsion of sweet basil oil possessed higher activity than that of holy basil oil [92]. Australian essential oil, Backhousia citriodora, was shown to possess 
significant antimicrobial activity against S. aureus, E. coli, $P$. aeruginosa, C. albicans, methicillin resistant $S$. aureus, $A$. niger, K. pneumoniae, and $P$. acnes [93].

Essential oils of Citrus aurantium, Eucalyptus radiate, Juniperus communis, Pelargonium asperum, Pogostemon cablin, and Styrax benzoe have been used in the treatment of acne [94]. In addition, essential oils of Anthemis aciphylla, Salvia desoleana, and S. sclarea showed weak to moderate inhibitory effect against $S$. aureus and S. epidermidis. Tamarix bovena essential oil was found to inhibit facial flora that would be applicable in acne treatment [95].

Helianthus annuus and Cucurbita pepo seed oils as well as flax or linseed oil, having mainly linoleic and linolenic acids, were used for dermatological treatments including acne. Besides the above mentioned natural oils, Prunus armeniaca, Argania spinosa, Persea gratissima, Adansonia digitata, Ribes nigrum, Vaccinium macrocarpon, Zea mays, Oenothera biennis, Vitis vinifera, Corylus Americana, Schinziophyton rautanenii, Moringa oleifera, Elaeis guineensis, Papaver orientale, Brassica napus, Rubus idaeus, Oryza sativa, Carthamus tinctorius, Sesamum indicum, Glycine soja, Prunus amygdalus, and Juglans regia oils are known to be used in the treatment of acne [72]. These scientific findings recommend the vital role of essential oils in possible customized therapeutic regimens for acne management.

4.3. Phytomolecules. Plants contain a broad range of medicinally active chemical components or phytoconstituents that account for their medicinal properties. The first target after obtaining an active extract is identification, isolation, and characterization of plant extract bioactive phytomolecule(s). Recently many scientific reports signify the applications of isolated phytomolecules in targeting acne lesions through various mechanisms which are summarized below.

Rhodomyrtone, principle compound of Rhodomyrtus tomentosa leaves, was tested against $P$. acnes (MIC $0.5 \mu \mathrm{g} / \mathrm{mL}$ ) using broth macrodilution method and was reported to be significantly effective by reducing $99 \%$ of the bacterial cells within 24 hours. Cytotoxicity test performed on human normal fibroblast indicated very low cytotoxicity favouring its use as topical therapeutic antiacne agent [96]. Pulsaquinone and hydropulsaquinone isolated from extract of the roots of Pulsatilla koreana exhibited antimicrobial activity against $P$. acnes with MIC values of 2.0 and $4.0 \mu \mathrm{g} / \mathrm{mL}$, respectively, [97]. Furthermore, Brazilin, protosappanin A, and sappanone $\mathrm{B}$, isolated from methanolic extracts of Caesalpinia sappan wood, showed significant lipase inhibitory and antibacterial activity with MIC values of $0.50 \mathrm{mg} / \mathrm{mL}, 1.00 \mathrm{mg} / \mathrm{mL}$, and $>2.00 \mathrm{mg} / \mathrm{mL}$, respectively. The antioxidant activity of brazilin and protosappanin A was also found to be appreciably higher than sappanone B [98]. Similarly, the ethyl acetate extract of Momordica charantia (wild bitter melons) contains phytol and lutein as bioactive constituents which strongly suppressed proinflammatory cytokine and MMP9 levels in P. acnes stimulated THP-1 cells, attenuated ear swelling and granulomatous inflammation, and activated PRAR $a$ and $b$ in the transactivation assay [99]. Further ent-kaurene diterpenoids, namely, rosthornins A-D, isolated from the dried leaves ether extract of Rabdosia rosthornii, exhibited antibacterial activity specifically against $P$. acnes $(3.17-25 \mu \mathrm{g} / \mathrm{mL})[100]$.

The active compound berberine from Rhizoma coptidis exerted anti-inflammatory effects through a negative regulation of COX-2 and API as well as by inhibition of lipoxygenases [101]. Its extract showed its anti-inflammatory effect by inhibiting the expression of various proinflammatory cytokines and cell surface molecules involved in inflammatory responses at the transcriptional level [102]. Flavonoids like kaempferol and quercetin, isolated from Impatiens balsamina in combination with clindamycin and erythromycin, were found to be potent against antibiotic resistant $P$. acnes with MIC values of $\leq 32 \mu \mathrm{g} / \mathrm{mL}$ and $\leq 64 \mu \mathrm{g} / \mathrm{mL}$, respectively, [103]. Likewise, honokiol and magnolol isolated from Magnolia spp. evidenced potent antibacterial activities against $P$. acnes and $P$. granulosum, by disk diffusion method with MIC 3-4 $\mu \mathrm{g} / \mathrm{mL}$ and $9 \mu \mathrm{g} / \mathrm{mL}$, respectively. Additionally, their killing curve analysis showed that $P$. acnes was rapidly killed within 10 min of treatment at the rate of 105 organisms per $\mathrm{mL}$. They also reduced the secretion of IL- 8 and TNF- $\alpha$ induced by $P$. acnes in THP-1 cells indicating their antiinflammatory effects [104].

A new abietane diterpene, 2b-acetoxyferruginol, isolated from the stem bark of Prumnopitys andina, had antibacterial activity assayed against $P$. acnes and was found to be most active at the concentration of $4 \mu \mathrm{g} / \mathrm{mL}$ [105]. Panduratin A, a natural chalcone compound isolated from Kaempferia pandurata, has noteworthy in vitro antistaphylococcal activity against clinical staphylococcal isolates [106]. Mahonia aquifolium stem bark crude extract and its protoberberine alkaloids, berberine, and jatrorrhizine revealed antimicrobial activity against twenty strains of coagulase negative staphylococci and P. acnes (MIC 5-50 $\mu \mathrm{g} / \mathrm{mL}$ ) isolated from skin lesions of acne patients [107]. Epimedium brevicornum and Polygonum cuspidatum extracts and their active compounds icariin, resveratrol, and salidroside were identified to possess marked antibiofilm activity against $P$. acnes when used in subinhibitory concentrations [108].

Naturally derived components, xanthohumol and lupulones from Hupulus lumulus, illustrated strong inhibitory activity against $P$. acnes (MIC $0.1-3 \mu \mathrm{g} / \mathrm{mL}$ ), S. epidermidis, $S$. aureus, K. rhizophila, and $S$. pyogenes. These compounds in addition to humulones demonstrated moderate to strong anticollagenase inhibitory activities. Xanthohumo, also showed the highest total oxygen radical absorbance capacity and singlet oxygen absorbance capacity thereby proving its antioxidative potential [109]. Flavonoids $2^{\prime}, 6^{\prime}$-dihydroxy$3^{\prime}$-methyl-4'-methoxy-dihydrochalcone, eucalyptin, and 8-desmethyl-eucalyptin, isolated from E. maculata extracts, considerably inhibited the growth of $S$. aureus, MRSA, $B$. cereus, E. faecalis, A. acidoterrestris, $P$. acnes, and $T$. mentagrophytes, with MIC ranging from 1.0 to $31 \mathrm{mg} / \mathrm{L}$ [110]. Several saponins and flavonoids, namely, $\beta$-aescin, digitonin, kaempferol, and catechin showed strong lipase inhibitory activity with low toxicity thereby confirming there use against acne [111]. 
Bakuchiol obtained from the edible seeds of Psoralea corylifolia showed strong antibacterial effects, anticollagenase, COX-2, COX-1, and expression of inducible nitric oxide synthase genes inhibitory activity. It has broad spectrum antioxidant activity, effectively quenches superoxide, hydroxy, peroxy, peroxynitrile radicals, and singlet oxygen non radicals in addition to inhibiting lipid peroxidation. A pilot clinical study showed that $1 \%$ bakuchiol reduced acne by a score of about $57 \%$, whereas $2 \%$ salicylic acid only reduced acne by about $48 \%$, but when used in combination it reduced acne lesions and inflammation upto 70\% [112]. It has been reported that the fruits and root of $A$. dahurica containing imperatorin, phellopterin, xantoroxin, byakangelcol, oxypeucedanin, neobyakangelcol, and coumarin markedly suppressed neutrophil chemotaxis. Similarly, Coptis chinensis root and stem, containing high concentrations of berberine, have strong antilipogenic effect; furthermore, G. glabra containing glycyrrhizine, triterpene glycoside, glabric acid, flavanones, and isoflavones showed remarkable antibacterial activity against $P$. acnes [113].

Wogonin (5,7-dihydroxy-8-methoxyflavone) isolated from the methanolic extract of Scutellaria baicalensis potently lowered mRNA levels of COX-2, TNF- $\alpha$, and PGE2 in a subchronic skin inflammation model of tetradecanoylphorbol-13-acetate induced ear edema. It also affected intercellular adhesion molecule-1 and IL-1b but to a lesser extent [114]. Rutaecarpine, a quinazolinocarboline alkaloid, evodiamine, dehydroevodiamine, and triterpenoid evodin, isolated from unripe fruit extract of Evodia rutaecarpa, inhibited ultraviolet A induced ROS generation, resulting in the enhanced expression of MMP-2 and MMP9 in human skin cells. It also inhibited $\mathrm{H}_{2} \mathrm{O}_{2}$ induced increase in the expression of MMP-2 and MMP-9, COX-2, and phospholipase A2 [115]. Matrine, baicalin, ursolic acid, sodium danshensu, hesperidin, and andrographolide significantly reduced IL- 8 and TNF- $\alpha$ by human $\mathrm{HaCaT}$ keratinocyte cells pretreated with heat-killed $P$. acnes [116]. Extracts from Terminalia chebula and Embelia ribes showed lipase inhibition, chebulagic acid being the responsible component for antilipase activity, with MIC of $12.5 \mu \mathrm{g} / \mathrm{mL}$ against $P$. acnes [117]. Among various compounds isolated from the methanolic extract of the seeds of Arctium lappa, namely,isolappaol C, lappaol C, lappaol D, lappaol F, and diarctigenin, the latter two strongly inhibited NO production in the LPS-stimulated RAW264.7 cells [118].

Geraniin, isolated from Phyllanthus embelica, showed strong activity in DPPH and lipid peroxidation assays as well as NO scavenging activity [72, 119]. Anthemis nobilis and Matricaria recutita were employed in skin inflammation due to their biologically active flavonoids, particularly apigenin, $\alpha$-bisabolol, and chamazulene [72]. Rhinacanthin-C (82.59\%) isolated from Rhinacanthus nasutus extract was quoted to have potent bactericidal activity against $S$. mutans and $P$. acnes with MIC values of $2-8 \mu \mathrm{g} / \mathrm{mL}$, respectively, [120].

A recent study explored the inhibitory potential of rosmarinic acid, a phenolic compound from Rosmarinus officinalis, with MIC values $62.5 \mu \mathrm{g} / \mathrm{mL}$ and $31.25 \mu \mathrm{g} / \mathrm{mL}$ against $P$. acnes and $S$. aureus, respectively, [121]. In a study, out of 10 flavonoids isolated from Intsia palembanica methanolic extract, fustin, ampelopsin and $4^{\prime}$-dehydroxyrobidanol were found to be the most active compounds to inhibit the lipase activity of $P$. acnes using the 2,3-dimercapto-1-propanol tributyrate (BALB) method with IC50 values of $13.7 \mu \mathrm{M}$, $36.1 \mu \mathrm{M}$, and $40.0 \mu \mathrm{M}$, respectively, [122]. Epigallocatechin3 -gallate, the major polyphenol in green tea, was found to reduce sebum by modulating the AMPK-SREBP-1 signaling pathway and inflammation through suppression of NF- $\kappa \mathrm{B}$ and AP-1 pathways. These findings were supported by an 8-week randomized, split-face, and clinical trial where the molecule significantly improved acne and was found to be well tolerated [123].

Signs of acne are evident as dark spots (hyperpigmentation) and scars on the affected skin surface, which is due to overexpression and accumulation of melanin regulated by the enzyme tyrosinase. It was confirmed in a study that Artocarpus integer root extract possessed tyrosinase inhibition potential (90.57\%) and antimicrobial activity against $S$. aureus, S. epidermidis, P. acnes, and T. mentagophytes. Compounds isolated from the above plant extract, artocarpin and cudraflavone $\mathrm{C}$, showed the potent antibacterial activity against $S$. aureus, S. epidermidis, and P. acnes with MIC at 2, 4, and $2 \mu \mathrm{g} / \mathrm{mL}$, respectively, whereas artocarpanone exhibited antityrosinase potential [124].

The above discussion regarding the scope of natural therapeutics in the form of plant extracts, essential oils, and various isolated phytomolecules spell out the worth of plant derived treatment options against acne vulgaris. These findings also propose their broad relevance against $P$. acnes, directly or indirectly via similar mechanisms as that of synthetic molecules, like anti-inflammatory, antioxidative, anticollagenase, antielastase, and antimicrobial activities with lesser side effects.

\section{Overview of Various Novel Drug Delivery Strategies}

In case of dermatological pharmacotherapy, for the treatment of skin inflammatory and infectious disorders like acne, the dermal delivery of active ingredients is desirable. Topical application of antiacne agents assures many advantages over oral or intravenous administration such as it offers avoidance of first pass metabolism and elimination of gastrointestinal irritation. Skin being an effective barrier for foreign permeation encumbers the access of antiacne agents to the pathologic site, thereby decreasing its bioavailability. Therefore, the topical dosage forms against acne should be designed such that topical dosage form facilitates the delivery of active moiety to the target site that is pilosebaceous unit of the skin. With this intention, an intelligently framed delivery system encapsulating the active moiety should be developed appending specific ligands to target the active site overcoming the biological barriers.

The encapsulation of antiacne drugs in vesicular and particulate delivery system represents an innovative alternative to minimize the related side effects, while preserving their efficacy. Novel drug delivery strategies can play a pivotal role in improving the topical delivery of antiacne agents 


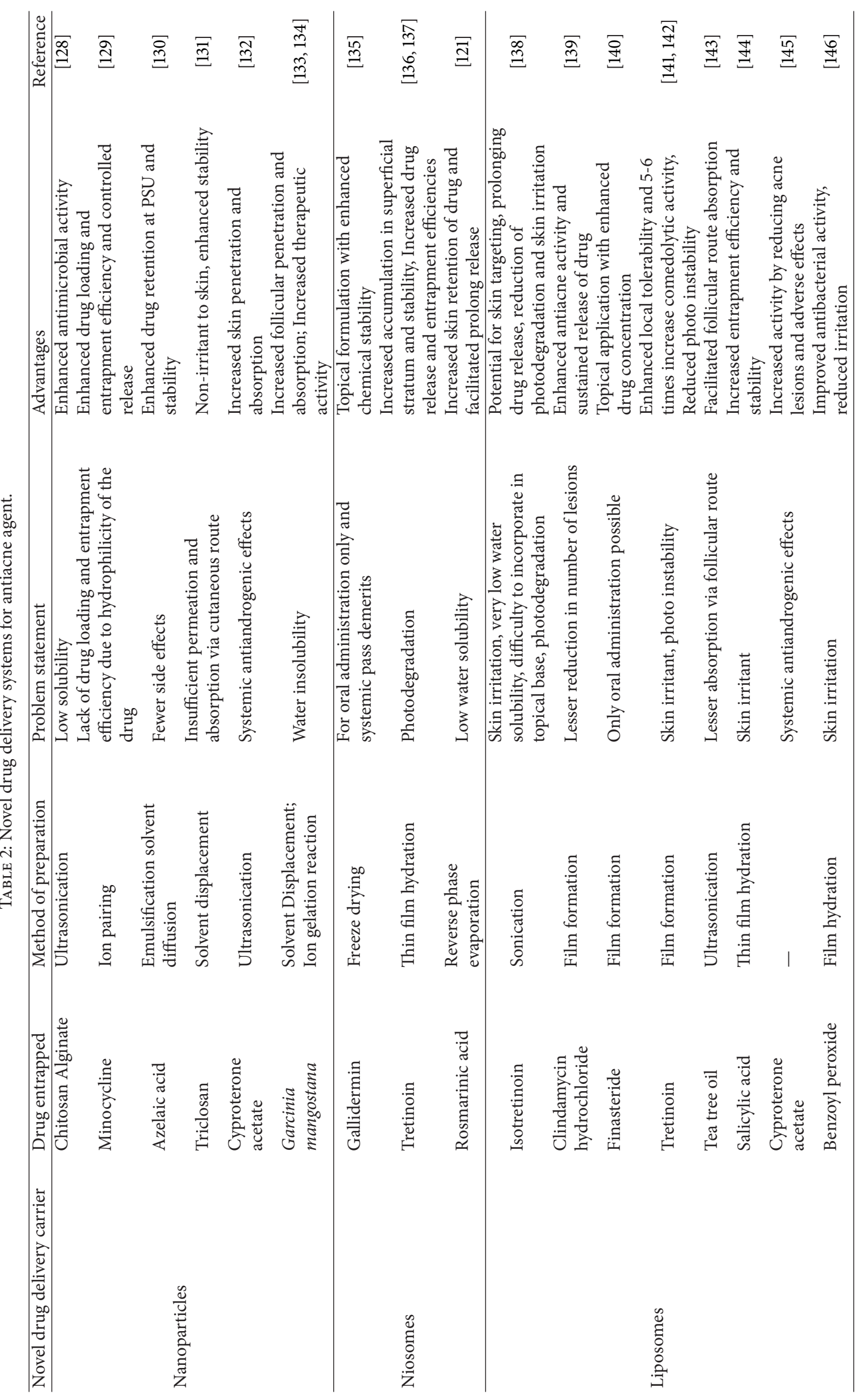




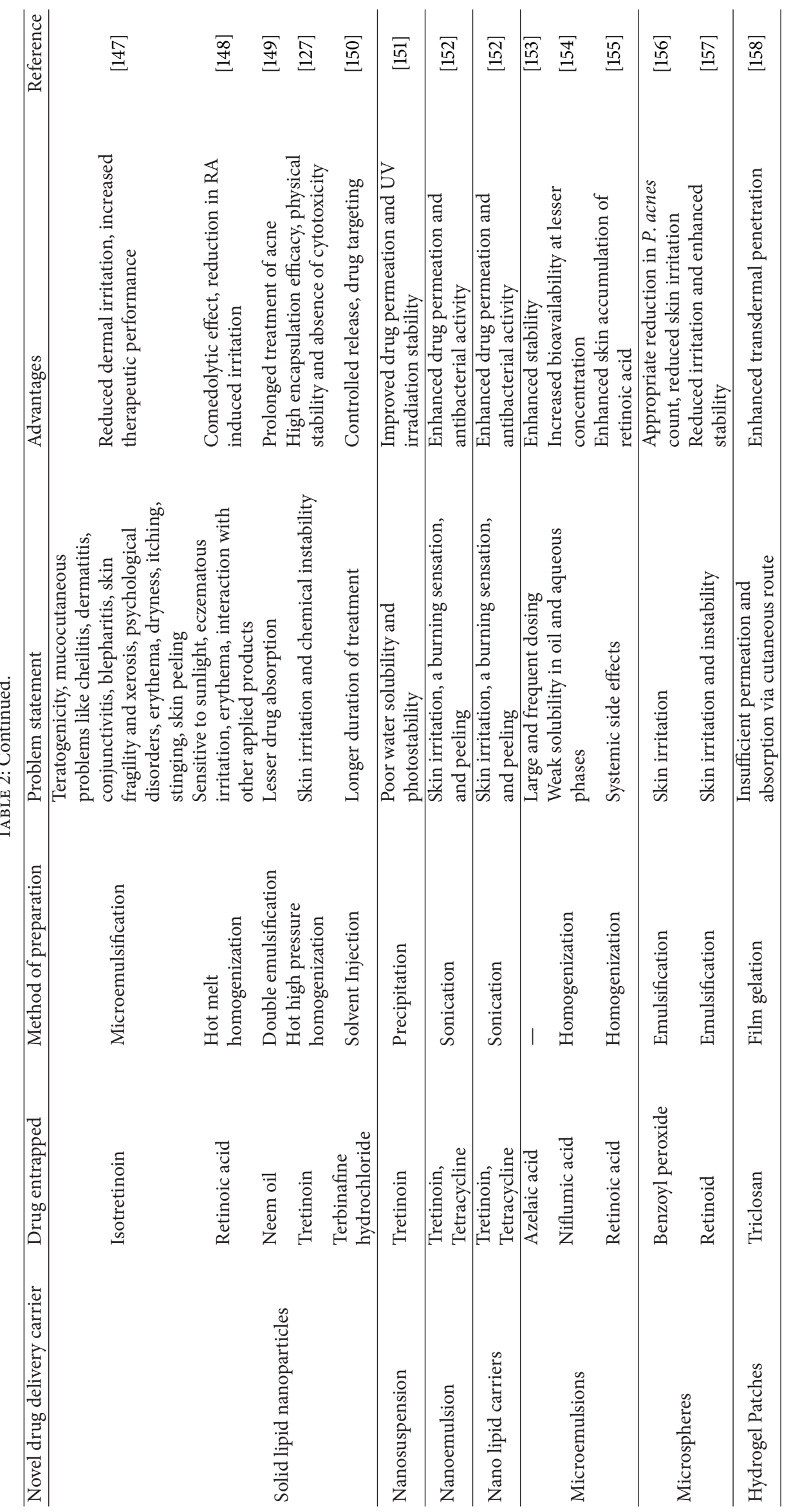


by enhancing their dermal localization with a concomitant reduction in their side effects. Research is encouraging towards a growing commitment in the development of new technologies to optimize delivery systems that may overcome technical hitches by influencing drug release, improving retention of the drug through targeting and reducing local drug toxicity, lowering dose of active agents and combination therapy, and harnessing more potent drugs which cannot clinically be utilized through conventional drug delivery. Various drug delivery carriers recently explored to beat acne vulgaris are nanoparticles, liposomes, niosomes, solid lipid nanoparticles, nanoemulsions, and nanosuspensions. In fact, their ability in improving the topical delivery of antiacne agents has been very well established by in vitro experiments $[125,126]$. In a recent study, solid lipid nanoparticles with chitosan containing tretinoin were prepared and characterized, which showed high encapsulation efficiency, high physical stability, and absence of cytotoxicity in keratinocytes. It also exhibited antibacterial activity against $P$. acnes, thereby increasing the therapeutic efficacy of tretinoin in the topical treatment of acne [127]. Further investigations are needed, however, to allow the large scale production of novel drug delivery systems at lower costs. Finally, complementary efforts are required to validate the ability of these strategies in enhancing topical treatment of acne. A brief description of these novel carriers, their method of preparations, and advantages have been summarized in Table 2 .

\section{Conclusion}

Although there are numerous drug therapies for the treatment of acne (topical, systemic retinoid, antibiotics, and keratolytics), the foremost challenge is the growing concerns of rising antibiotic resistance and dermal toxicities with existing medications. The authors praise natural remedies as an alternative against acne over these synthetic drugs. These developing natural therapies cover naturally derived drugs from active plant extracts, essential oils, and phytomolecules which are discussed in the review. However, there are certain issues allied to natural therapies, for example; while considering plant extracts, it is necessary to define the quality and safety of extracts. These problems can be resolved through standardization by advance analytical techniques (HPLC, HPTLC, GC, and LC-MS/MS). Essential oil and phytomolecule, despite having excellent bioactivity in vitro, demonstrate less or no in vivo actions due to their volatility, irritation, poor lipid solubility, or improper molecular size, resulting poor absorption, and bioavailability. These hitches could be overcome by incorporating the active moiety in some novel carrier that will reduce the chance of direct contact of active moiety with environment and skin surface; thereby, they prove to be less irritating (an advantage attributed to controlled release). Moreover, the overall cost in formulating novel carriers is lower than the conventional ones giving similar activity, because it requires less frequent administration and less intervention for toxicity. Furthermore, lack of an animal model which would purely mimic histologic and immunophenotypic characteristics of acne is another major challenge as this dreadful disease usually occurs only in humans. Depending upon the expressed cytokines in the acne lesions, an anti-inflammatory model with emphasis on major cytokines involved can be the better option. Androgens (DHEAS, testosterone, and DHT) and other related enzymes (5- $\alpha$ reductase, anticoligenase, and elastase) being the initiator of sebocyte differentiation that contributes in sebum hyperproduction as well as hyperkeratinization can be easily mimicked in small animal models as a target for novel moieties. Comedolytic and antioxidant activities in the rabbit model can be future animal targets. Also, the molecular targets that modulate several key pathological factors of acne can be aimed to optimize the therapeutic outcome. Hence, currently we can say that still a lot of expertise and experience are needed in this area as plant drugs have massive potential against $P$. acnes which should be explored through some value added drug delivery systems.

\author{
Abbreviations \\ NCEs: New chemical entities \\ MIC: Minimum inhibitory concentration \\ MBC: Minimum bactericidal concentration \\ DHEAS: Dehydroepiandrosterone \\ DHT: Dihydrotestosterone \\ TLR2: Toll like receptors \\ IL: Interleukin \\ GMCSF: Granulocyte macrophage colony stimulating \\ factor \\ CYP21: Cytochrome P21 \\ PPAR $\gamma$ : Peroxisome proliferator activating receptor \\ MMP: Matrix metalloproteinase \\ IGF: Insulin growth factor \\ FGFR: Fibroblast growth factor receptor \\ DP IV: Dipeptidyl peptidase IV \\ APN: Aminopeptidase N \\ CRH: Corticotrophin releasing hormone \\ HPLC: High performance liquid chromatography \\ ELISA: Enzyme linked immunosorbent assay \\ NOS: Nitric oxide synthase \\ COX: Cyclooxygenase \\ PGE2: Prostaglandin E2 \\ LPS: Lipopolysaccharide \\ NDDS: Novel drug delivery system.
}

\section{Conflict of Interests}

The authors state no conflict of interests.

\section{Acknowledgments}

The authors are thankful to SERB, for providing fund in the form of fast track young scientist project to Dr. Narayan Prasad Yadav, and to Council of Scientific and Industrial Research (CSIR), New Delhi, for providing financial assistance to one of the author as CSIR-GATE JRF (Grant no. 31/GATE/34(02)/2012-EMR-I). This work was also supported by CSIR-Central Institute of Medicinal and Aromatic Plants 
(CSIR-CIMAP), Lucknow, as it provided the necessary facilities.

\section{References}

[1] W. P. Bowe and A. C. Logan, "Acne vulgaris, probiotics and the gut-brain-skin axis-back to the future?" Gut Pathogens, vol. 3, no. 1, article 1, pp. 1-11, 2011.

[2] H. C. Williams, R. P. Dellavalle, and S. Garner, "Acne vulgaris," The Lancet, vol. 379, no. 9813, pp. 361-372, 2012.

[3] T. Coenye, E. Peeters, and H. J. Nelis, "Biofilm formation by Propionibacterium acnes is associated with increased resistance to antimicrobial agents and increased production of putative virulence factors," Research in Microbiology, vol. 158, no. 4, pp. 386-392, 2007.

[4] G. Webster, "Acne vulgaris," The British Medical Journal, vol. 325, no. 7362, pp. 475-479, 2002.

[5] R. Nguyen and J. Su, “Treatment of acne vulgaris," Paediatrics and Child Health, vol. 21, no. 3, pp. 119-125, 2011.

[6] H. Safizadeh, S. Shamsi-Meymandy, and A. Naeimi, "Quality of life in Iranian patients with acne," Dermatology Research and Practice, vol. 2012, Article ID 571516, 4 pages, 2012.

[7] A. M. Layton, "Acne vulgaris and similar eruptions," Medicine, vol. 33, no. 1, pp. 44-48, 2005.

[8] I. Truter, “Acne vulgaris," SA Pharmaceutical Journal, vol. 76, no. 3, pp. 12-19, 2009.

[9] I. Brajac, L. Bilić-Zulle, M. Tkalčić, K. Lončarek, and F. Gruber, "Acne vulgaris: myths and misconceptions among patients and family physicians," Patient Education and Counseling, vol. 54, no. 1, pp. 21-25, 2004.

[10] F. H. Sakamoto, L. Torezan, and R. R. Anderson, "Photodynamic therapy for acne vulgaris: a critical review from basics to clinical practice: Part II. Understanding parameters for acne treatment with photodynamic therapy," Journal of the American Academy of Dermatology, vol. 63, no. 2, pp. 195-211, 2010.

[11] K. Bhate and H. C. Williams, "Epidemiology of acne vulgaris.", The British journal of dermatology, vol. 168, no. 3, pp. 474-485, 2013.

[12] B. Adityan and D. M. Thappa, "Profile of acne vulgaris-A hospital-based study from South India," Indian Journal of Dermatology, Venereology and Leprology, vol. 75, no. 3, pp. 272278, 2009.

[13] T. Schäfer, A. Nienhaus, D. Vieluf, J. Berger, and J. Ring, "Epidemiology of acne in the general population: the risk of smoking," British Journal of Dermatology, vol. 145, no. 1, pp. 100 104, 2001.

[14] A. N. Feneran, W. S. Kaufman, T. S. Dabade, and S. R. Feldman, "Retinoid plus antimicrobial combination treatments for acne," Clinical, Cosmetic and Investigational Dermatology, vol. 4, pp. 79-92, 2011.

[15] H. Gollnick, W. Cunliffe, D. Berson et al., "Management of acne: a report from a global alliance to improve outcomes in acne," Journal of the American Academy of Dermatology, vol. 49, no. 1, pp. S1-S37, 2003.

[16] E. Makrantonaki, R. Ganceviciene, and C. Zouboulis, "An update on the role of the sebaceous gland in the pathogenesis of acne," Dermato-Endocrinology, vol. 3, no. 1, pp. 41-49, 2011.

[17] M. Toyoda and M. Morohashi, "Pathogenesis of acne," Medical Electron Microscopy, vol. 34, no. 1, pp. 29-40, 2001.
[18] I. Kurokawa, F. W. Danby, Q. Ju et al., "New developments in our understanding of acne pathogenesis and treatment," Experimental Dermatology, vol. 18, no. 10, pp. 821-832, 2009.

[19] E. C. Davis and V. D. Callender, "A review of acne in ethnic skin: pathogenesis, clinical manifestations, and management strategies," Journal of Clinical and Aesthetic Dermatology, vol. 3, no. 4, pp. 24-38, 2010.

[20] V. K. Ghosh, D. H. Nagore, K. P. Kadbhane, and M. J. Patil, "Different approaches of alternative medicines in acne vulgaris treatment," Oriental Pharmacy and Experimental Medicine, vol. 11, no. 1, pp. 1-9, 2011.

[21] C. C. Zouboulis, "Sebaceous gland receptors," Dermato-Endocrinology, vol. 1, no. 2, pp. 77-80, 2009.

[22] M. Ottaviani, E. Camera, and M. Picardo, "Lipid mediators in acne," Mediators of Inflammation, vol. 2010, Article ID 858176, 6 pages, 2010.

[23] B. C. Melnik and G. Schmitz, "Role of insulin, insulin-like growth factor-1, hyperglycaemic food and milk consumption in the pathogenesis of acne vulgaris," Experimental Dermatology, vol. 18, no. 10, pp. 833-841, 2009.

[24] M. Cappel, D. Mauger, and D. Thiboutot, "Correlation between serum levels of insulin-like growth factor 1, dehydroepiandrosterone sulfate, and dihydrotestosterone and acne lesion counts in adult women," Archives of Dermatology, vol. 141, no. 3, pp. 333-338, 2005.

[25] B. C. Melnik, "Role of FGFR2-signaling in the pathogenesis of acne," Dermato-Endocrinology, vol. 1, no. 3, pp. 141-156, 2009.

[26] B. C. Melnik, G. Schmitz, and C. C. Zouboulis, "Anti-acne agents attenuate FGFR2 signal transduction in acne," Journal of Investigative Dermatology, vol. 129, no. 8, pp. 1868-1877, 2009.

[27] C. C. Zouboulis, H. Seltmann, N. Hiroi et al., "Corticotropinreleasing hormone: an autocrine hormone that promotes lipogenesis in human sebocytes," Proceedings of the National Academy of Sciences of the United States of America, vol. 99, no. 10, pp. 7148-7153, 2002.

[28] R. Ganceviciene, V. Graziene, S. Fimmel, and C. C. Zouboulis, "Involvement of the corticotropin-releasing hormone system in the pathogenesis of acne vulgaris," British Journal of Dermatology, vol. 160, no. 2, pp. 345-352, 2009.

[29] O. Isard, A. C. Knol, N. Castex-Rizzi et al., "Cutaneous induction of corticotropin releasing hormone by Propionibacterium acnes extracts," Dermato-Endocrinology, vol. 1, no. 2, pp. 96-99, 2009.

[30] E. Papakonstantinou, A. J. Aletras, E. Glass et al., "Matrix metalloproteinases of epithelial origin in facial sebum of patients with acne and their regulation by isotretinoin," The Journal of Investigative Dermatology, vol. 125, no. 4, pp. 673-684, 2005.

[31] D. Meyer-Rogge and I. L. Kruglikov, "Pilot study into superfractionation treatment strategy of acne and rosacea," Journal of Cosmetics, Dermatological Sciences and Applications, vol. 3, no. 3, pp. 197-202, 2013.

[32] A. Thielitz, D. Reinhold, R. Vetter et al., "Inhibitors of dipeptidyl peptidase IV and aminopeptidase $\mathrm{N}$ target major pathogenetic steps in acne initiation," Journal of Investigative Dermatology, vol. 127, no. 5, pp. 1042-1051, 2007.

[33] A. Thielitz, S. Ansorge, U. Bank et al., "The ectopeptidases dipeptidyl peptidase IV (DP IV) and aminopeptidase N (APN) and their related enzymes as possible targets in the treatment of skin diseases," Frontiers in Bioscience, vol. 13, no. 6, pp. 23642375, 2008. 
[34] H. Gollnick and M. Schramm, "Topical therapy in acne," Journal of the European Academy of Dermatology and Venereology, vol. 11, supplement 1, pp. S8-S12, 1998.

[35] S. Ramanathan and A. A. Hebert, "Management of acne vulgaris," Journal of Pediatric Health Care, vol. 25, no. 5, pp. 332337, 2011.

[36] J. Bensouilah, "Aetiology and management of Acne vulgaris," International Journal of Aromatherapy, vol. 12, no. 2, pp. 99-104, 2002.

[37] W. P. Bowe and A. R. Shalita, "Effective over-the-counter acne treatments," Seminars in Cutaneous Medicine and Surgery, vol. 27, no. 3, pp. 170-176, 2008.

[38] A. Haider and J. C. Shaw, "Treatment of acne vulgaris," Journal of the American Medical Association, vol. 292, no. 6, pp. 726-735, 2004.

[39] L. Shaw and C. Kennedy, "The treatment of acne," Current Paediatrics, vol. 13, no. 6, pp. 423-428, 2003.

[40] R. George, S. Clarke, and D. Thiboutot, "Hormonal therapy for acne," Seminars in Cutaneous Medicine and Surgery, vol. 27, no. 3, pp. 188-196, 2008.

[41] J. J. Leyden, "A review of the use of combination therapies for the treatment of acne vulgaris," Journal of the American Academy of Dermatology, vol. 49, no. 3, pp. S200-S210, 2003.

[42] N. Malhotra, T. E. Pyra, and J. Rao, "Real word acne therapy in primary care," Clinical Medicine Insights: Dermatology, vol. 5, pp. 29-43, 2012.

[43] S. Kapoor and S. Saraf, "Topical herbal therapies an alternative and complementary choice to combat acne," Research Journal of Medicinal Plant, vol. 5, no. 6, pp. 650-669, 2011.

[44] M. T. Chomnawang, S. Surassmo, V. S. Nukoolkarn, and W. Gritsanapan, "Antimicrobial effects of Thai medicinal plants against acne-inducing bacteria," Journal of Ethnopharmacology, vol. 101, no. 1-3, pp. 330-333, 2005.

[45] M. Sharma, R. Schoop, A. Suter, and J. B. Hudson, "The potential use of Echinacea in acne: control of Propionibacterium acnes growth and inflammation," Phytotherapy Research, vol. 25, no. 4, pp. 517-521, 2011.

[46] W. Pothitirat, M. T. Chomnawang, and W. Gritsanapan, "Antiacne-inducing bacterial activity of mangosteen fruit rind extracts," Medical Principles and Practice, vol. 19, no. 4, pp. 281286, 2010.

[47] M. T. Chomnawang, S. Surassmo, V. S. Nukoolkarn, and W. Gritsanapan, "Effect of Garcinia mangostana on inflammation caused by Propionibacterium acnes," Fitoterapia, vol. 78, no. 6, pp. 401-408, 2007.

[48] J. Lee, J. S. Shim, M. Chung, S. Lim, and K. H. Kim, "In vitro anti-adhesive activity of green tea extract against pathogen adhesion," Phytotherapy Research, vol. 23, no. 4, pp. 460-466, 2009.

[49] T. Mahmood, N. Akhtar, B. A. Khan, H. M. S. Khan, and T. Saeed, "Outcomes of $3 \%$ green tea emulsion on skin sebum production in male volunteers," Bosnian Journal of Basic Medical Sciences, vol. 10, no. 3, pp. 260-264, 2010.

[50] P. Nand, S. Drabu, and R. K. Gupta, "Phytochemical and antimicrobial screening of medicinal plants for the treatment of acne," Indian Journal of Natural Products and Resources, vol. 3, no. 1, pp. 28-32, 2012.

[51] P. Panichayupakaranant, S. Tewtrakul, and S. Yuenyongsawad, "Antibacterial, anti-inflammatory and anti-allergic activities of standardised pomegranate rind extract," Food Chemistry, vol. 123, no. 2, pp. 400-403, 2010.
[52] F. Qa'dan, A. Thewaini, D. A. Ali, R. Afifi, A. Elkhawad, and K. Z. Matalka, "The antimicrobial activities of Psidium guajava and Juglans regia leaf extracts to acne-developing organisms," The American Journal of Chinese Medicine, vol. 33, no. 2, pp. 197204, 2005.

[53] S. S. Joo, S. K. Jang, S. G. Kim, J.-S. Choi, K. W. Hwang, and D. I. Lee, "Anti-acne activity of Selaginella involvens extract and its non-antibiotic antimicrobial potential on Propionibacterium acnes," Phytotherapy Research, vol. 22, no. 3, pp. 335-339, 2008.

[54] A. Vijayalakshmi, A. Tripura, and V. Ravichandiran, "Development and evaluation of anti-acne products from Terminalia arjuna Bark," International Journal of PharmTech Research, vol. 3, no. 1, pp. 320-327, 2011.

[55] T. S. Thring, P. Hili, and D. P. Naughton, "Antioxidant and potential anti-inflammatory activity of extracts and formulations of white tea, rose, and witch hazel on primary human dermal fibroblast cells," Journal of Inflammation, vol. 8, article 27, 7 pages, 2011.

[56] T. H. Tsai, W. H. Wu, J. T. P. Tseng, and P. J. Tsai, "In vitro antimicrobial and anti-inflammatory effects of herbs against Propionibacterium acnes," Food Chemistry, vol. 119, no. 3, pp. 964-968, 2010.

[57] A. Jain and E. Basal, "Inhibition of Propionibacterium acnesinduced mediators of inflammation by Indian herbs," Phytomedicine, vol. 10, no. 1, pp. 34-38, 2003.

[58] G. S. Kumar, K. N. Jayaveera, and C. K. Ashok Kumar, "Antimicrobial effects of Indian medicinal plants against acne-inducing bacteria," Tropical Journal of Pharmaceutical Research, vol. 6, no. 2, pp. 717-723, 2007.

[59] A. Pieroni, C. L. Quave, M. L. Villanelli et al., "Ethnopharmacognostic survey on the natural ingredients used in folk cosmetics, cosmeceuticals and remedies for healing skin diseases in the inland Marches, Central-Eastern Italy," Journal of Ethnopharmacology, vol. 91, no. 2-3, pp. 331-344, 2004.

[60] A. de Natale and A. Pollio, "Plants species in the folk medicine of Montecorvino Rovella (inland Campania, Italy)," Journal of Ethnopharmacology, vol. 109, no. 2, pp. 295-303, 2007.

[61] S. S. Kim, C. G. Hyun, J. Y. Kim, J. Lee, and D. Park, "Antibacterial effects of medicinal plants from jeju island against acneinducing bacteria," Journal of Applied Biological Chemistry, vol. 50, no. 2, pp. 101-103, 2007.

[62] M. M. Cowan, "Plant products as antimicrobial agents," Clinical Microbiology Reviews, vol. 12, no. 4, pp. 564-582, 1999.

[63] S. S. Kim, J. Y. Kim, N. H. Lee, and C. G. Hyun, "Antibacterial and anti-inflammatory effects of Jeju medicinal plants against acne-inducing bacteria," The Journal of General and Applied Microbiology, vol. 54, no. 2, pp. 101-106, 2008.

[64] I. Batubara, T. Mitsunaga, and H. Ohashi, "Screening antiacne potency of Indonesian medicinal plants: antibacterial, lipase inhibition, and antioxidant activities," Journal of Wood Science, vol. 55, no. 3, pp. 230-235, 2009.

[65] U. Mabona, A. Viljoen, E. Shikanga, A. Marston, and S. van Vuuren, "Antimicrobial activity of southern African medicinal plants with dermatological relevance: from an ethnopharmacological screening approach, to combination studies and the isolation of a bioactive compound," Journal of Ethnopharmacology, vol. 148, no. 1, pp. 45-55, 2013.

[66] G. S. Kumar, K. N. Jayaveera, C. K. A. Kumar et al., "Antibacterial screening of selected Indian medicinal plants against acne inducing bacteria," Pharmacologyonline, vol. 2, pp. 34-47, 2007.

[67] T. Aburjai and F. M. Natsheh, "Plants used in cosmetics," Phytotherapy Research, vol. 17, no. 9, pp. 987-1000, 2003. 
[68] J. Reuter, I. Merfort, and C. M. Schempp, "Botanicals in dermatology: an evidence-based review," The American Journal of Clinical Dermatology, vol. 11, no. 4, pp. 247-267, 2010.

[69] E. Yarnell and K. Abascal, "Herbal medicine for acne vulgaris," Alternative and Complementary Therapies, vol. 12, no. 6, pp. 303-309, 2006.

[70] N. Khan, R. Karodi, A. Siddiqui, S. Thube, and R. Rub, "Development of anti-acne gel formulation of anthraquinones rich fraction from Rubia cordifolia (Rubiaceae)," International Journal of Applied Research in Natural Products, vol. 4, no. 4, pp. 28-36, 2011.

[71] A. M. Gorle and S. S. Patil, "Evaluation of antioxidant and antiacne property of Rubia cordifolia," Der Pharmacia Sinica, vol. 1, pp. 59-63, 2010.

[72] M. Kanlayavattanakul and N. Lourith, "Therapeutic agents and herbs in topical application for acne treatment," International Journal of Cosmetic Science, vol. 33, no. 4, pp. 289-297, 2011.

[73] K. C. S. Kumar and K. Müller, "Medicinal plants from Nepal; II. Evaluation as inhibitors of lipid peroxidation in biological membranes," Journal of Ethnopharmacology, vol. 64, no. 2, pp. 135-139, 1999.

[74] P. Chaturvedi, "Inhibitory response of Raphanus sativus on lipid peroxidation in albino rats," Evidence-Based Complementary and Alternative Medicine, vol. 5, no. 1, pp. 55-59, 2008.

[75] J. Gou, Y. Zou, and J. Ahn, "Enhancement of antioxidant and antimicrobial activities of Dianthus superbus, Polygonum aviculare, Sophora flavescens, and Lygodium japonicum by pressureassisted water extraction," Food Science and Biotechnology, vol. 20, no. 1, pp. 283-287, 2011.

[76] I. B. Bassett, D. L. Pannowitz, and R. S. C. Barnetson, "A comparative study of tea-tree oil versus benzoylperoxide in the treatment of acne," Medical Journal of Australia, vol. 153, no. 8, pp. 455-458, 1990.

[77] A. Raman, U. Weir, and S. F. Bloomfield, "Antimicrobial effects of tea-tree oil and its major components on Staphylococcus aureus, Staph. Epidermidis and Propionibacterium acnes," Letters in Applied Microbiology, vol. 21, no. 4, pp. 242-245, 1995.

[78] S. Enshaieh, A. Jooya, A. H. Siadat, and F. Iraji, "The efficacy of $5 \%$ topical tea tree oil gel in mild to moderate acne vulgaris: a randomized, double-blind placebo-controlled study," Indian Journal of Dermatology, Venereology and Leprology, vol. 73, no. 1, pp. 22-25, 2007.

[79] P. Pithayanukul, J. Tubprasert, and M. Wuthi-Udomlert, "In vitro antimicrobial activity of Zingiber cassumunar (Plai) oil and a 5\% Plai oil gel," Phytotherapy Research, vol. 21, no. 2, pp. 164169, 2007.

[80] T. H. Oh, S. S. Kim, W. J. Yoon et al., "Chemical composition and biological activities of Jeju Thymus quinquecostatus essential oils against Propionibacterium species inducing acne," The Journal of General and Applied Microbiology, vol. 55, no. 1, pp. 63-68, 2009.

[81] Y. Fu, Y. Zu, L. Chen et al., "Investigation of antibacterial activity of rosemary essential oil against Propionibacterium acnes with atomic force microscopy," Planta Medica, vol. 73, no. 12, pp. 1275-1280, 2007.

[82] S. Athikomkulchai, R. Watthanachaiyingcharoen, and S. Tunvichien, "The development of anti-acne products from Eucalyptus globulus and Psidium Guajava oil," Journal of Health Research, vol. 22, no. 3, pp. 109-113, 2008.

[83] D. Bhatt, A. K. Sachan, S. Jain, and R. Barik, "Studies on inhibitory effect of Eucalyptus oil on sebaceous glands for the management of acne," Indian Journal of Natural Products and Resources, vol. 2, no. 3, pp. 345-349, 2011.
[84] W.-J. Yoon, S.-S. Kim, T.-H. Oh, N. H. Lee, and C.-G. Hyun, "Abies koreana essential oil inhibits drug-resistant skin pathogen growth and lps-induced inflammatory effects of murine macrophage," Lipids, vol. 44, no. 5, pp. 471-476, 2009.

[85] A. Vats and P. Sharma, "Formulation \& evaluation of topical anti acne formulation of coriander oil," International Journal of Pharmacy and Pharmaceutical Science Research, vol. 2, no. 3, pp. 61-66, 2012.

[86] S. S. Kim, J. S. Baik, T. H. Oh, W. Yoon, N. H. Lee, and C. Hyun, "Biological activities of Korean Citrus obovoides and Citrus natsudaidai essential oils against acne-inducing bacteria," Bioscience, Biotechnology and Biochemistry, vol. 72, no. 10, pp. 2507-2513, 2008.

[87] W. J. Yoon, S. S. Kim, T. H. Oh, H. L. Nam, and C. G. Hyun, "Cryptomeria japonica essential oil inhibits the growth of drugresistant skin pathogens and LPS-induced nitric oxide and proinflammatory cytokine production," Polish Journal of Microbiology, vol. 58, no. 1, pp. 61-68, 2009.

[88] L. O. Orafidiya, E. O. Agbani, A. O. Oyedele, O. O. Babalola, and O. Onayemi, "Preliminary clinical tests on topical preparations of Ocimum gratissimum linn leaf essential oil for the treatment of Acne vulgaris," Clinical Drug Investigation, vol. 22, no. 5, pp. 313-319, 2002.

[89] L. O. Orafidiya, E. O. Agbani, A. O. Oyedele, O. O. Babalola, O. Onayemi, and F. F. Aiyedun, "The effect of Aloe vera gel on the anti-acne properties of the essential oil of Ocimum gratissimum Linn leaf-a preliminary clinical investigation," International Journal of Aromatherapy, vol. 14, no. 1, pp. 15-21, 2004.

[90] P. Lertsatitthanakorn, S. Taweechaisupapong, C. Aromdee, and W. Khunkitti, "In vitro bioactivities of essential oils used for acne control," International Journal of Aromatherapy, vol. 16, no. 1, pp. 43-49, 2006.

[91] Y. Zu, H. Yu, L. Liang et al., "Activities of ten essential oils towards Propionibacterium acnes and PC-3, A-549 and MCF-7 cancer cells," Molecules, vol. 15, no. 5, pp. 3200-3210, 2010.

[92] J. Viyoch, N. Pisutthanan, A. Faikreua, K. Nupangta, K. Wangtorpol, and J. Ngokkuen, "Evaluation of in vitro antimicrobial activity of Thai basil oils and their micro-emulsion formulas against Propionibacterium acnes," International Journal of Cosmetic Science, vol. 28, no. 2, pp. 125-133, 2006.

[93] A. J. Hayes and B. Markovic, "Toxicity of Australian essential oil Backhousia citriodora (Lemon myrtle). Part 1. Antimicrobial activity and in vitro cytotoxicity," Food and Chemical Toxicology, vol. 40, no. 4, pp. 535-543, 2002.

[94] C. J. Stevensen, "Aromatherapy in dermatology," Clinics in Dermatology, vol. 16, no. 6, pp. 689-694, 1998.

[95] H. Azimi, M. Fallah-Tafti, A. A. Khakshur, and M. Abdollahi, "A review of phytotherapy of Acne vulgaris: perspective of new pharmacological treatments," Fitoterapia, vol. 83, no. 8, pp. 1306-1317, 2012.

[96] J. Saising and S. P. Voravuthikunchai, "Anti Propionibacterium acnes activity of rhodomyrtone, an effective compound from Rhodomyrtus tomentosa (Aiton) Hassk. leaves," Anaerobe, vol. 18, no. 4, pp. 400-404, 2012.

[97] S. C. Cho, M. Z. Sultan, and S. S. Moon, "Anti-acne activities of pulsaquinone, hydropulsaquinone, and structurally related 1 , 4-quinone derivatives," Archives of Pharmacal Research, vol. 32, no. 4, pp. 489-494, 2009.

[98] I. Batubara, T. Mitsunaga, and H. Ohashi, "Brazilin from Caesalpinia sappan wood as an antiacne agent," Journal of Wood Science, vol. 56, no. 1, pp. 77-81, 2010. 
[99] C. Hsu, T.-H. Tsai, Y.-Y. Li, W.-H. Wu, C.-J. Huang, and P.-J. Tsai, "Wild bitter melon (Momordica charantia Linn. var. abbreviata Ser.) extract and its bioactive components suppress Propionibacterium acnes-induced inflammation," Food Chemistry, vol. 135, no. 3, pp. 976-984, 2012.

[100] I. Kubo, Y. Xu, and K. Shimizu, "Antibacterial Activity of entKaurene Diterpenoids from Rabdosia rosthornii," Phytotherapy Research, vol. 18, no. 2, pp. 180-183, 2004.

[101] R. Enk, R. Ehehalt, J. E. Graham, A. Bierhaus, A. Remppis, and H. J. Greten, "Differential effect of Rhizoma coptidis and its main alkaloid compound berberine on TNF- $\alpha$ induced NF $\kappa \mathrm{B}$ translocation in human keratinocytes," Journal of Ethnopharmacology, vol. 109, no. 1, pp. 170-175, 2007.

[102] J. M. Kim, H. A. Jung, J. S. Choi, and N. G. Lee, "Identification of anti-inflammatory target genes of Rhizoma coptidis extract in lipopolysaccharide-stimulated RAW264.7 murine macrophage-like cells," Journal of Ethnopharmacology, vol. 130, no. 2, pp. 354-362, 2010.

[103] Y. Lim, I. Kim, and J. Seo, "In vitro activity of kaempferol isolated from the Impatiens balsamina alone and in combination with erythromycin or clindamycin against Propionibacterium acnes," Journal of Microbiology, vol. 45, no. 5, pp. 473-477, 2007.

[104] J. Park, J. Lee, E. Jung et al., "In vitro antibacterial and anti-inflammatory effects of honokiol and magnolol against Propionibacterium sp.," European Journal of Pharmacology, vol. 496, no. 1, pp. 189-195, 2004.

[105] E. C. J. Smith, N. Wareham, M. Zloh, and S. Gibbons, " $2 \beta$-Acetoxyferruginol-a new antibacterial abietane diterpene from the bark of Prumnopitys andina," Phytochemistry Letters, vol. 1, no. 1, pp. 49-53, 2008.

[106] Y. Rukayadi, K. Lee, S. Han, D. Yong, and J. K. Hwang, "Invitro activities of panduratin A against clinical Staphylococcus strains," Antimicrobial Agents and Chemotherapy, vol. 53, no. 10, pp. 4529-4532, 2009.

[107] L. Slobodníková, D. KoSt'álová, D. Labudová, D. Kotulová, and V. Kettmann, "Antimicrobial activity of Mahonia aquifolium crude extract and its major isolated alkaloids," Phytotherapy Research, vol. 18, no. 8, pp. 674-676, 2004.

[108] T. Coenye, G. Brackman, P. Rigole et al., "Eradication of Propionibacterium acnes biofilms by plant extracts and putative identification of icariin, resveratrol and salidroside as active compounds," Phytomedicine, vol. 19, no. 5, pp. 409-412, 2012.

[109] N. Yamaguchi, K. Satoh-Yamaguchi, and M. Ono, "In vitro evaluation of antibacterial, anticollagenase, and antioxidant activities of hop components (Humulus lupulus) addressing Acne vulgaris," Phytomedicine, vol. 16, no. 4, pp. 369-376, 2009.

[110] T. Takahashi, R. Kokubo, and M. Sakaino, "Antimicrobial activities of eucalyptus leaf extracts and flavonoids from Eucalyptus maculata," Letters in Applied Microbiology, vol. 39, no. 1, pp. 6064, 2004.

[111] C. Ruiz, S. Falcocchio, E. Xoxi et al., "Inhibition of Candida rugosa lipase by saponins, flavonoids and alkaloids," Journal of Molecular Catalysis B: Enzymatic, vol. 40, no. 3-4, pp. 138-143, 2006.

[112] R. K. Chaudhuri and F. Marchio, "Bakuchiol in the management of acne-affected skin," Cosmetics \& Toiletries Magazine, vol. 126, no. 7, pp. 502-510, 2011.

[113] C. Nam, S. Kim, Y. Sim, and I. Chang, "Anti-acne effects of oriental herb extracts: a novel screening method to select antiacne agents," Skin Pharmacology and Applied Skin Physiology, vol. 16, no. 2, pp. 84-90, 2003.
[114] Y. S. Chi, H. Lim, H. Park, and H. P. Kim, "Effects of wogonin, a plant flavone from Scutellaria radix, on skin inflammation: in vivo regulation of inflammation-associated gene expression," Biochemical Pharmacology, vol. 66, no. 7, pp. 1271-1278, 2003.

[115] S. Beak, S. Paek, Y. Jahng, Y. S. Lee, and J. Kim, "Inhibition of UVA irradiation-modulated signaling pathways by rutaecarpine, a quinazolinocarboline alkaloid, in human keratinocytes," European Journal of Pharmacology, vol. 498, no. 1-3, pp. 19-25, 2004.

[116] S. Fu, C. Sun, X. Tao, and Y. Ren, "Anti-inammatory effects of active constituents extracted from Chinese medicinal herbs against Propionibacterium acnes," Natural Product Research, vol. 26, no. 18, pp. 1746-1749, 2012.

[117] V. Patil, A. Bandivadekar, and D. Debjani, "Inhibition of Propionibacterium acnes lipase by extracts of Indian medicinal plants," International Journal of Cosmetic Science, vol. 34, no. 3, pp. 234-239, 2012.

[118] S. Y. Park, S. S. Hong, X. H. Han et al., "Lignans from Arctium lappa and their inhibition of LPS-induced nitric oxide production," Chemical and Pharmaceutical Bulletin, vol. 55, no. 1, pp. 150-152, 2007.

[119] A. Kumaran and R. J. Karunakaran, "Nitric oxide radical scavenging active components from Phyllanthus emblica L.," Plant Foods for Human Nutrition, vol. 61, no. 1, pp. 1-5, 2006.

[120] P. Puttarak, T. Charoonratana, and P. Panichayupakaranant, "Antimicrobial activity and stability of rhinacanthins-rich Rhinacanthus nasutus extract," Phytomedicine, vol. 17, no. 5, pp. 323-327, 2010.

[121] A. Budhiraja and G. Dhingra, "Development and characterization of a novel antiacne niosomal gel of rosmarinic acid," Drug Delivery, 2014.

[122] I. Batubara, H. Kuspradini, A. M. Muddathir, and T. Mitsunaga, "Intsia palembanica wood extracts and its isolated compounds as Propionibacterium acnes lipase inhibitor," Journal of Wood Science, vol. 60, pp. 169-174, 2014.

[123] J. Y. Yoon, H. H. Kwon, S. U. Min, D. M. Thiboutot, and D. H. Suh, "Epigallocatechin-3-gallate improves acne in humans by modulating intracellular molecular targets and inhibiting $P$. acnes," Journal of Investigative Dermatology, vol. 133, no. 2, pp. 429-440, 2013.

[124] S. Dej-adisai, I. Meechai, J. Puripattanavong, and S. Kummee, "Antityrosinase and antimicrobial activities from Thai medicinal plants," Archives of Pharmacal Research, vol. 37, no. 4, pp. 473-483, 2014.

[125] G. A. Castro and L. A. M. Ferreira, "Novel vesicular and particulate drug delivery systems for topical treatment of acne," Expert Opinion on Drug Delivery, vol. 5, no. 6, pp. 665-679, 2008.

[126] A. A. Date, B. Naik, and M. S. Nagarsenker, "Novel drug delivery systems: potential in improving topical delivery of antiacne agents," Skin Pharmacology and Physiology, vol. 19, no. 1, pp. 216, 2006.

[127] D. M. Ridolfi, P. D. Marcato, G. Z. Justo, L. Cordi, D. Machado, and N. Durán, "Chitosan-solid lipid nanoparticles as carriers for topical delivery of tretinoin," Colloids and Surfaces B: Biointerfaces, vol. 93, pp. 36-40, 2012.

[128] A. J. Friedman, J. Phan, D. O. Schairer et al., "Antimicrobial and anti-inflammatory activity of chitosan-alginate nanoparticles: a targeted therapy for cutaneous pathogens," The Journal of Investigative Dermatology, vol. 133, no. 5, pp. 1231-1239, 2013.

[129] T. S. J. Kashi, S. Eskandarion, M. Esfandyari-Manesh et al., "Improved drug loading and antibacterial activity of minocyclineloaded PLGA nanoparticles prepared by solid/oil/water ion 
pairing method," International Journal of Nanomedicine, vol. 7, pp. 221-234, 2012.

[130] C. P. Reis, A. Gomes, P. Rijo et al., "Development and evaluation of a novel topical treatment for acne with azelaic acid-loaded nanoparticles," Microscopy and Microanalysis, vol. 19, no. 5, pp. 1141-1150, 2013.

[131] C. L. Domínguez-Delgado, I. M. Rodríguez-Cruz, J. J. EscobarChávez, I. O. Calderón-Lojero, D. Quintanar-Guerrero, and A. Ganem, "Preparation and characterization of triclosan nanoparticles intended to be used for the treatment of acne," European Journal of Pharmaceutics and Biopharmaceutics, vol. 79, no. 1, pp. 102-107, 2011.

[132] J. Štecová, W. Mehnert, T. Blaschke et al., "Cyproterone acetate loading to lipid nanoparticles for topical acne treatment: particle characterisation and skin uptake," Pharmaceutical Research, vol. 24, no. 5, pp. 991-1000, 2007.

[133] E. Rismana, S. Kusumaningrum, O. Bunga, Nizar, and Marhamah, "Determination of antiacnes activity of chitosan-Garcinia mangostana extract nanoparticles," Media Litbangkes, vol. 24, pp. 19-27, 2014.

[134] A. Tachaprutinun, M. C. Meinke, H. Richter et al., "Comparison of the skin penetration of Garcinia mangostana extract in particulate and non-particulate form," European Journal of Pharmaceutics and Biopharmaceutics, vol. 86, pp. 307-313, 2014.

[135] A. Manosroi, P. Khanrin, W. Lohcharoenkal et al., "Transdermal absorption enhancement through rat skin of gallidermin loaded in niosomes," International Journal of Pharmaceutics, vol. 392, no. 1-2, pp. 304-310, 2010.

[136] M. Manconi, C. Sinico, D. Valenti, G. Loy, and A. M. Fadda, "Niosomes as carriers for tretinoin. I. Preparation and properties," International Journal of Pharmaceutics, vol. 234, no. 1-2, pp. 237-248, 2002.

[137] M. Manconi, C. Sinico, D. Valenti, F. Lai, and A. M. Fadda, "Niosomes as carriers for tretinoin: III. A study into the in vitro cutaneous delivery of vesicle-incorporated tretinoin," International Journal of Pharmaceutics, vol. 311, no. 1-2, pp. 11-19, 2006.

[138] N. Kaur, R. Puri, and S. K. Jain, "Drug-cyclodextrin-vesicles dual carrier approach for skin targeting of anti-acne agent," AAPS PharmSciTech, vol. 11, no. 2, pp. 528-537, 2010.

[139] N. Škalko, M. Čajkovac, and I. Jalšenjak, "Liposomes with clindamycin hydrochloride in the therapy of Acne vulgaris," International Journal of Pharmaceutics, vol. 85, no. 1-3, pp. 97101, 1992.

[140] M. Tabbakhian, N. Tavakoli, M. R. Jaafari, and S. Daneshamouz, "Enhancement of follicular delivery of finasteride by liposomes and niosomes. 1. In vitro permeation and in vivo deposition studies using hamster flank and ear models," International Journal of Pharmaceutics, vol. 323, no. 1-2, pp. 1-10, 2006.

[141] C. Sinico, M. Manconi, M. Peppi, F. Lai, D. Valenti, and A. M. Fadda, "Liposomes as carriers for dermal delivery of tretinoin: in vitro evaluation of drug permeation and vesicleskin interaction," Journal of Controlled Release, vol. 103, no. 1, pp. 123-136, 2005.

[142] M. Brisaert, M. Gabriëls, V. Matthijs, and J. Plaizier-Vercammen, "Liposomes with tretinoin: a physical and chemical evaluation," Journal of Pharmaceutical and Biomedical Analysis, vol. 26, no. 5-6, pp. 909-917, 2001.

[143] S. S. Biju, A. Ahuja, and R. K. Khar, "Tea tree oil concentration in follicular casts after topical delivery: determination by high-performance thin layer chromatography using a perfused bovine udder model," Journal of Pharmaceutical Sciences, vol. 94, no. 2, pp. 240-245, 2005.

[144] S. S. Bhalerao and A. R. Harshal, "Preparation, optimization, characterization, and stability studies of salicylic acid liposomes," Drug Development and Industrial Pharmacy, vol. 29, no. 4, pp. 451-467, 2003.

[145] D. M. Gruber, M. O. Sator, E. A. Joura, E. M. Kokoschka, G. Heinze, and J. C. Huber, "Topical cyproterone acetate treatment in women with acne: a placebo-controlled trial," Archives of Dermatology, vol. 134, no. 4, pp. 459-463, 1998.

[146] J. W. Fluhr, O. Barsom, W. Gehring, and M. Gloor, "Antibacterial efficacy of benzoyl peroxide in phospholipid liposomes," Dermatology, vol. 198, no. 3, pp. 273-277, 1999.

[147] K. Raza, B. Singh, P. Singal, S. Wadhwa, and O. P. Katare, "Systematically optimized biocompatible isotretinoin-loaded solid lipid nanoparticles (SLNs) for topical treatment of acne," Colloids and Surfaces B: Biointerfaces, vol. 105, pp. 67-74, 2013.

[148] G. A. Castro, C. A. Oliveira, G. A. B. Mahecha, and L. A. M. Ferreira, "Comedolytic effect and reduced skin irritation of a new formulation of all-trans retinoic acid-loaded solid lipid nanoparticles for topical treatment of acne," Archives of Dermatological Research, vol. 303, no. 7, pp. 513-520, 2011.

[149] V. Vijayan, S. Aafreen, S. Sakthivel, and K. R. Reddy, "Formulation and characterization of solid lipid nanoparticles loaded Neem oil for topical treatment of acne," Journal of Acute Disease, vol. 2, no. 4, pp. 282-286, 2013.

[150] H. Vaghasiya, A. Kumar, and K. Sawant, "Development of solid lipid nanoparticles based controlled release system for topical delivery of terbinafine hydrochloride," European Journal of Pharmaceutical Sciences, vol. 49, no. 2, pp. 311-322, 2013.

[151] F. Lai, R. Pireddu, F. Corrias et al., "Nanosuspension improves tretinoin photostability and delivery to the skin," International Journal of Pharmaceutics, vol. 458, no. 1, pp. 104-109, 2013.

[152] C. Lin, Y. Fang, S. A. Al-Suwayeh, S. Yang, and J. Fang, "Percutaneous absorption and antibacterial activities of lipid nanocarriers loaded with dual drugs for acne treatment," Biological and Pharmaceutical Bulletin, vol. 36, no. 2, pp. 276-286, 2013.

[153] M. R. Gasco, M. Gallarate, and F. Pattarino, "In vitro permeation of azelaic acid from viscosized microemulsions," International Journal of Pharmaceutics, vol. 69, no. 3, pp. 193-196, 1991.

[154] M. A. Bolzinger, T. C. Carduner, and M. C. Poelman, "Bicontinuous sucrose ester microemulsion: a new vehicle for topical delivery of niflumic acid," International Journal of Pharmaceutics, vol. 176, no. 1, pp. 39-45, 1998.

[155] M. Trotta, E. Ugazio, E. Peira, and C. Pulitano, "Influence of ion pairing on topical delivery of retinoic acid from microemulsions," Journal of Controlled Release, vol. 86, no. 2-3, pp. 315-321, 2003.

[156] R. C. Wester, R. Patel, S. Nacht, J. Leyden, J. Melendres, and H. Maibach, "Controlled release of benzoyl peroxide from a porous microsphere polymeric system can reduce topical irritancy," Journal of the American Academy of Dermatology, vol. 24, no. 5, part 1, pp. 720-726, 1991.

[157] M. Froix, M. Pukshansky, and S. Nacht, "Retinoid formulations in porous microspheres for reduced irritation and enhanced stabilty," US Patent 5851538, 1998.

[158] T.-W. Lee, J.-C. Kim, and S.-J. Hwang, "Hydrogel patches containing Triclosan for acne treatment," European Journal of Pharmaceutics and Biopharmaceutics, vol. 56, no. 3, pp. 407-412, 2003. 

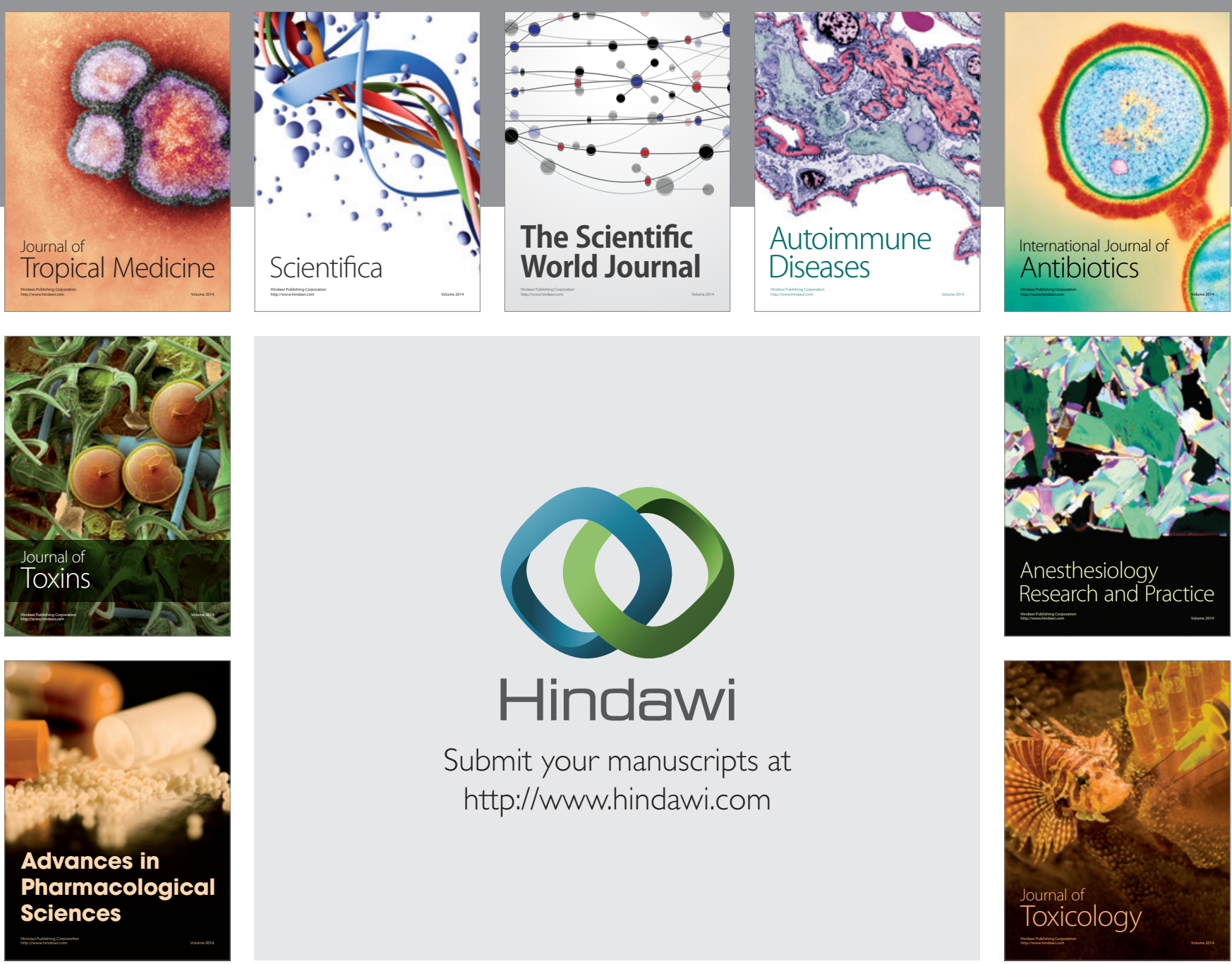

\section{Hindawi}

Submit your manuscripts at

http://www.hindawi.com
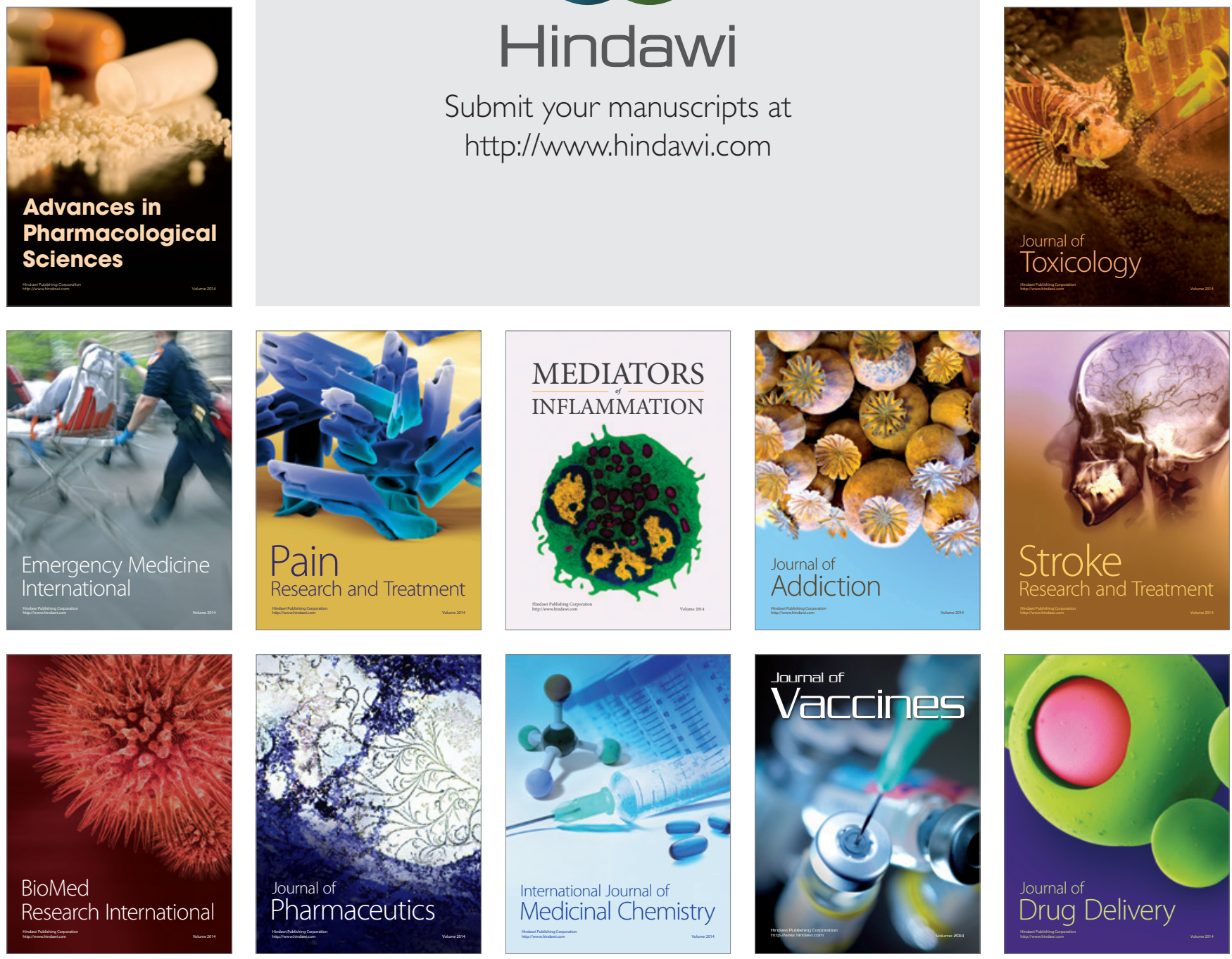